\title{
Applying Complexity Theory to Deepen Service Dominant Logic: Configural Analysis of Customer Experience-and-Outcome Assessments of Professional Services for Ephemeral Personal Transformations
}

\author{
Pei-Ling Wu, Chienkuo Technology University, Taiwan \\ Shih-Shuo Yeh, National Quemoy University, Taiwan \\ Tzung-Cheng (T.C.) Huan (corresponding author), National Chiayi University, Taiwan \\ Arch G. Woodside, Boston College, United States
}

Submission: January 2014

Revision: February 2014

Accepted: March 2014

The authors appreciate the comments by Carol Megehee, Coastal Carolina University, on a draft of this article. Send correspondence to Pei-Ling Wu, Chienkuo Technology University, Department of Beauty Science and Graduate Institute of Beauty Science, No.1, Chien Shou N. Road, Changhua City, Taiwan 500, Fax: 886-4-7111171, E-mail: pauline@ @ctu.edu.tw; ShihShuo Yeh, Department of Tourism Management, National Quemoy University, 1, University RD., Jinning, Kinmen 89250, Taiwan, Phone: 886-(0)935-989-605, Email: yesso5@yahoo.com.tw; Tzung-Cheng (T.C.) Huan (corresponding author), College of Management, National Chiayi University, 580, Hsin-Ming Rd., Chiayi 60054, Taiwan, Phone: 886-5-2751573, Fax: 886-5-2732805, Email: tchuan@mail.ncyu.edu.tw; Arch G. Woodside, Boston College, Department of Marketing, 140 Commonwealth Avenue, Chestnut Hill, MA 02467, telephone/fax: 1-617-332-3609/6677; arch.woodside@bc.edu. 


\title{
Applying Complexity Theory to Deepen Service Dominant Logic: Configural Analysis of Customer Experience-and-Outcome Assessments of Ephemeral Professional Services for Personal Transformations
}

\begin{abstract}
This article reports theory and examines data in ways that transcend the dominant logics for variable-based and case-based analyses. The theory and data analysis tests key propositions in complexity theory, for example, no single antecedent condition is a sufficient or necessary indicator of a high score in an outcome condition; a few complex configurations of antecedent conditions are sufficient indicators of high scores in an outcome condition. The study tests and supports these propositions in the context of customer assessments $(n=436)$ of service facets and service outcome evaluations for assisted ephemeral transformations of self via beauty salon and spa treatments. The findings advance a nuanced theory of how customers' service evaluations relate to their assessments of overall service quality and intentions to use the service. The findings support the need for service managers to be vigilant in fine-tuning service facets and service enactments to achieve high customer retention.
\end{abstract}

Keywords: beauty salon; complexity; configuration; contrarian; transformation 


\section{Introduction: Complexity and Customer Evaluations of Service Enactments and Outcomes}

Mann Zhang reports being very happy with his new metro-look outcome following his visit, haircut, and styling at Miao’s Beauty Salon \& Spa; Mann also reports that he intends not to return to Miao's shop in the future. A second customer, Lin Chu, reports that Miao's is dark and generally unattractive inside but she gives very positive ratings to Miao for overall service quality. The first of these two anecdotal stories is an example of a "negative contrarian case"-a specific case of a positive indicator and negative outcome relationship while most other cases support a positive main effect between an indicator and an outcome. The second anecdote is an example of a "positive contrarian case" - a specific case of a negative indicator and positive outcome while most cases support a negative main effect between the indicator (e.g., poor ambience) and the outcome (e.g., overall service quality).

The present article contributes a radically new perspective in the service dominant logic literature (SDL, e.g., Lusch, 2006a, 2006b; Vargo \& Lusch, 2004a, 2004b; Vargo \& Lusch, 2006; Vargo \& Morgan, 2005) in three principal ways. The study here explains how complexity theory provides a solid foundation for advancing a radically new SDL theory; describes how the use of Boolean algebra and asymmetric analytics rather than matrix algebra and symmetric analytics provides a means for testing major tenets of complexity theory in SDL contexts; presents an empirical study of complexity theory tenets that includes comparing findings from symmetric testing with the alternative logic of asymmetric testing. The study's four foundational footings include (1) prior work that emphasizes how method selection affects theory perspective (Gigerenzer, 1991); (2) the contention that the low $\mathrm{R}^{21}$ s obtained in regression analysis lead to false conclusions about the ability of socioeconomic variables as well as attitudinal measures to substantially explain variance in dependent variables since $\mathrm{R}^{2}$ is a measure of a model's ability to 
predict individual rather than group behavior (Bass, Tigert, \& Lonsdale, 1968); (3) how models applying Boolean-based asymmetric analytics (Ragin, 2008) solves the symmetric analytic problems observed by Bass et al. (1968) by transcending variable and case level data analysis; and (4) advances in applying McClelland's (1998) algorithm solutions for overcoming the limitations of symmetric-based (e.g., ANOVA and regression) analytics. The findings support the perspective that such thinking and testing of complexity theory tenets via asymmetric methods provides a radically new and useful advance to the SDL literature.

Examining data on customer evaluations of their service experiences (Cheng, Tseng, \& Woodside, 2013) supports the following observation. A few-to-substantial numbers of cases occur in studies that have independent $(\mathrm{X})$ and dependent $(\mathrm{Y})$ contrarian relationships to the hypotheses tested and supported by the main findings. For example, some customers dissatisfied with their service experiences and outcomes also respond that they intend to return to this same service provider while other customers highly satisfied with their service experiences and outcomes respond that they intend-not-to-return. Such cases are identifiable in data sets even when MRA indicates highly statistical significance in support of the main effects that positive evaluations of service facets and enactments associate with positive intentions-to-return. The study here proposes and demonstrates the use of configural analysis and modeling of indicator combinations of contrarian cases to deepen understanding of such relationships.

Second, and beyond the discussion of contrarian case analysis, focusing analytics on net effects restricts insight because no single independent variable $(\mathrm{X})$ explains substantial amounts of variation in customers' positive and negative evaluations ( $\left.\mathrm{Y}^{\prime} \mathrm{s}\right)$ — most observed relationships are asymmetrical but the tools used predominately in service research test for symmetrical relationships (Ragin, 2008). For this reason, analysis of variance (ANOVA), correlation, and 
multiple regression models (MRAs) offer low-to-moderate explanatory effect sizes of variations in evaluation outcomes under investigation (e.g., customer assessments of overall service quality and intention-to-use the service in the future). MRA findings in the customer service evaluation and satisfaction literature mostly report adjusted (for sample size) coefficients for determination

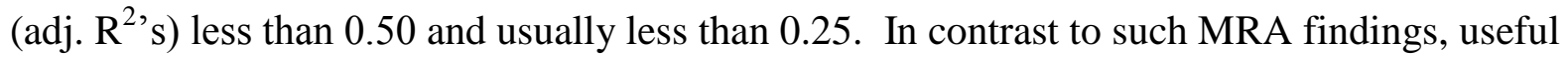
asymmetric configural models provide algorithms indicating that all or nearly all cases with relatively high values in the configural antecedent statements have relatively high values in the outcome condition - the "outcome condition" is analogous to the dependent variable in MRA.

The present study demonstrates the use of asymmetric tools for predicting high scores for an outcome condition using complex configurations that typically include combinations of threeto-seven simple antecedent conditions. To do so, the study includes testing for the associations of high scores for the complex antecedent conditions and high scores for the outcome conditions using appropriate computer software for performing such tests (e.g., fsQCA.com). Asymmetric testing makes no predictive claims for how an outcome (Y) relates to low configural indicator (X) scores - that is, Y scores are both low and high when $\mathrm{X}$ scores are low. The idea of creating and confirming the accuracy of configural statements associating with high scores for an outcome has great appeal for service executives because such configural statements indicate that if the service provider enacts combinatory service condition $\mathrm{C} \bullet \mathrm{T} \cdot \mathrm{H} \bullet \mathrm{Z}$ or $\mathrm{G} \bullet \mathrm{H} \bullet \mathrm{W} \bullet \mathrm{S}$, an attractive outcome will occur (e.g., customers experiencing each of these two complex antecedent combinations report high likelihood of using the service provider again) — the capital letters. The consonants $(\mathrm{C}, \mathrm{T}, \mathrm{H} \mathrm{S}, \mathrm{W}$, and $\mathrm{Z})$ in the two configural statements represent specific service facets and the mid-level dot, “•”, indicates the logical "and” procedure. For a beauty salon and spa, the consonants might include $\mathrm{C}=$ credentials of stylists and trainers; $\mathrm{T}=$ appealing aroma, 
temperature, lighting; $\mathrm{H}=$ attractive product displays; $\mathrm{S}=$ skill of personal service provider; $\mathrm{W}=$ pleasing word-of-mouth communications; $\mathrm{Z}=$ attractive architecture, decorations, and wallpaper.

The second configural statement (i.e., $\mathrm{G} \cdot \mathrm{H} \cdot \mathrm{W} \cdot \mathrm{S})$ indicates that a different configural statement from the first one associates with high scores in the outcome condition. Frequently, a few complex statements associate with high scores for an outcome condition. Different complex configural statements accurate in predicting high scores for the outcome condition usually include some of the same as well as unique individual cases. A logical "and" is a procedure in Boolean algebra whereby the total expression is equal to the lowest score occurring among the simple antecedents within the complex statement. Thus, for a specific case (customer) might respond with scores calibrated to include $\mathrm{C}=.95 ; \mathrm{T}=1.00 ; \mathrm{H}=.80 ; \mathrm{Z}=.87$, then $\mathrm{C} \cdot \mathrm{T} \cdot \mathrm{H} \cdot \mathrm{Z}=$ .80 .

The numerical scores are calibrated scores - a calibrated score is the result of a procedure of transforming original scores into membership scores for each specific antecedent or outcome condition-similar in purpose to transforming raw scores to z-scores in statistical hypothesis testing in regression analysis. Calibrated scores range from 0.00 to 1.00 for measures of all conditions - both antecedent and outcome conditions. A score of 0.80 for a complex antecedent condition would be quite high in most studies using fsQCA. If the configural model, $\mathrm{C} \cdot \mathrm{T} \bullet \mathrm{H} \bullet \mathrm{Z}$, was accurate/useful, then high scores (say for 9 cases for this statement) among the cases in the study (e.g., $\mathrm{n}=20$ to 3000 ), would associate with the occurrence of high scores in an outcome condition (e.g., 8 of the 9 cases have high scores in the outcome condition). Thus, if the analysis supports high accuracy for identifying high scores in the outcome condition, the expression in model 1 receives support as a useful model in predicting such occurrences: 


$$
\mathrm{C} \cdot \mathrm{T} \cdot \mathrm{H} \cdot \mathrm{Z} \leq \mathrm{U}
$$

where U equals scores for an outcome condition such as the customer's overall satisfaction with the service experienced. In research using Boolean algebra and testing for alternative configurations associating with high scores for an outcome condition, a "+" indicates "or" in a statement expressing different complex conditions:

$$
(\mathrm{C} \cdot \mathrm{T} \cdot \mathrm{H} \cdot \mathrm{Z})+(\mathrm{G} \cdot \mathrm{H} \cdot \mathrm{W} \cdot \mathrm{S}) \leq \mathrm{U}
$$

Equation 2 indicates that high scores for two complex antecedent configurations lead to the same outcome- high scores in U. Note that $\mathrm{H}$ appears in both complex models but each statement has combinations of simple antecedent conditions unique unto itself.

Following this introduction, section two presents core tenets of complexity theory. Section three describes the business context of the empirical study. Section four proposes complexity theory tenets for the specific industry business context. Section five covers the method of the study. Section six describes the findings. Section seven discusses the contributions of the study for theory and service management practice. Section eight concludes and includes limitations and recommendations for additional research.

\section{Complexity Theory in Service Research}

Most cases in a data set will have low scores for any given complex antecedent condition that predicts high scores in an outcome accurately for asymmetric models. Low scores on the complex antecedent condition associate with both low and high scores on the outcome condition. Figure 1 panel C illustrates such an asymmetric sufficient-but- not-necessary relationship for 26 hypothetical cases. For clarity purposes, Figure 1 includes displays of rectangular, symmetric, 
and asymmetric necessary-but-not-sufficient relationships. Unlike a symmetric Pearson $r$ index (a symmetric relationship appears visually in panel B in Figure 1), Boolean-related indexes for measuring the consistency of a given complex antecedent statement are unaffected by low and high scores for the outcome scores. Given the occurrence of contrarian cases in nearly all data sets, r's and adjusted $\mathrm{R}^{2}$ values almost never exceed 0.50 except for measuring reliability for multiple items in a scale for one construct; such symmetric-focused studies rarely consider modeling the indicators for the contrarian cases.

Figure 1 here.

The major tenets of complexity theory and qualitative comparative analysis (QCA) are relevant for attempting to deepen accurate explanation of how customers evaluate facets of services, enactments, and outcomes. These tenets include the proposition that a few (not one) of many possible paths lead to the same outcome, that is, "equifinality" occurs - alternative asymmetric combinations of indicators (i.e., algorithms) are sufficient but no one combination is necessary for accurately predicting customers' highly positive evaluations of service performance and high intentions to return to the same service provider.

A second complexity theory proposition is that, "Relationships between variables can be non-linear with abrupt switches occurring, so the same "cause" can, in specific circumstances, produce different effects" (Urry, 2005, p. 4). Thus, high customers' intentions to return may associate with an outcome of high overall service-quality assessments "in specific circumstances [contexts]" and an increase in demand may be an outcome of low overall service-quality assessments in other specific contexts. The same point is relevant for service antecedent and outcome conditions. 
The complexity turn to service research and theory includes the tipping-point tenet as Urry (2005) and Gladwell (2002) describe. Gladwell (2002) describes that if a system passes particular thresholds with minor changes in the controlling variables, switches occur such that a liquid turns into a gas, a large number of apathetic people suddenly tip into a forceful movement for change. "Such tipping points give rise to unexpected structures and events whose properties can be different form the underlying elementary laws" (Urry, 2005, p. 5). In asymmetric service research models such tipping points frequently involve replacing a negative with a positive response to one issue in a string (path) of questions-answers within a given complex configuration of antecedent conditions. Examples of such "causal complexity" (Ragin, 2000) appear in the empirical findings of the present study.

\section{Service-Provider and Customer Contexts in the Beauty and Spa Industry}

A planned objective of the study was to test tenets of complexity theory in a highlyintense personal service industry. The study focuses on a service high in physical and social contacts between customers and service providers - the beauty salon/spa industry. Several ethnographic studies of customers and stylists, physical-wellness trainers, and beauty salon/spa managers support the consistent finding that service enactments in this industry usually include 15 to 180 minutes of physical touching related to holding, shampooing/washing, massaging, hair-cutting, hair plucking, nail-filing, applying polish, waxing, hair-washing and dyeing, applications of lubricants/cosmetics, wrapping, drying, pedicures, and selling of cosmetics often with discussions, recommendations, and purchases of cosmetic products (Grimlin,1996; Otnes,

Ilhan, \& Kulkarni, 2012; Sharma Black, 2001; Toerien \& Kitzinger, 2007; Üstüner \& Thompson, 2012). 
In this high-touch •high-talk industry, the customer (and frequently the service provider) often engage in personal communications_-storytelling — about issues in life including relationships with significant others during service enactments. Both high-touch and high-talk together is a configurative statement that is integral within beauty and spa industry. Sharma and Black (2001, p. 926) report beauty therapists taking on a counsellor-like role when, for example, "clients confide about their family or marital problems in the course of a treatment." Toerien and Kitzinger, (2007, p. 654) emphasize, “... the relational side of salon work is far more pervasive than such instances imply. Emotional labor includes, crucially, the successful personalizing of an encounter that is utterly routine for the therapist.” As Sharma and Black (2001, p. 928) express, “At all costs the client must not feel that she is on a 'production line' served by a robot." Such lengthy and deep personal/physical touching and verbal communications offer rich, multi-step contexts representing multiple combinations of potentially positive and negative facets of service enactments - much more so than typical service enactments in most retail settings (e.g., department stores, banks, clothing stores, supermarkets, pharmacies, and gas stations).

The global personal care industry is valued at $\$ 300$ billion by Kline \& Company and growing by $4.5 \%$ annually (Matthews, 2013). The U.S. hair care services industry alone includes about 86,000 establishments ( 82,000 beauty salons; 4,000 barber shops) with combined annual revenue of about $\$ 20$ billion (Beauty Salon Business Overview \& Trends, 2012). The spa industry includes \$14 billion sales in the United States in 2012 (Big Five Statistics, 2013). In China, “beauty is big business"- the country's cosmetics market is worth $\$ 26$ billion a year, making it the third-largest globally. Euromonitor, a research firm, believes the cosmetics 
industry in China will grow $8 \%$ annually now through 2017. "Wages for the legions of 'beauty assistants"” are rising at double-digit rates annually in China (Because..., 2014, p. 57).

\section{Applying Complexity Theory Tenets in the Beauty and Spa Industry}

Figure 2 summarizes a general complexity theory (GCT) relevant for the beauty and spa industry — and to the entire discipline of service research following a few minor modifications. Rather than using primarily a boxes-and-arrow approach (cf. Sirgy, Grewal, \& Mangleburg, 2000), the GCT visual employs Venn diagrams to indicate the primary configural nature of complex antecedent conditions that indicate high scores in outcome conditions. This section describes major tenets of the GCT for the beauty salon and spa industry that are relevant for the retailing service sector more generally. The three bold-lines with upper case arrows $(\mathrm{A}, \mathrm{B}, \mathrm{C})$ in Figure 2 represent the major flows of configural relationships that the theory predicts; the three dotted-lines with lower case arrows (d, e, f) indicate peripheral routes that are likely to have lower consistencies in predicting high scores for outcome conditions.

Figure 2 here.

The first Venn diagram (left side of Figure 2) expresses the tenet that specific demographic configurations of customers affect their perceptions/evaluations of service facets and their overall assessment of service enactments. For clarity, only four simple demographic antecedents appear in Figure 2; of course, additional demographics are possible to include and are worthy of examination. With four demographics, 16-combinations occur: four simple antecedent conditions, six two-way, four three-way, and one four-way complex configurations. In comparison to the use of Boolean-based algorithm analysis and as Ragin (2008) emphasizes, considering these combinations as two-way, three-way, and four-way interaction effects in 
symmetrical statistical tests is difficult to interpret and to explain and presents multi-collinearity problems.

Because the literature in the behavioral sciences associates "hypothesis" with "statistical hypothesis testing" and because testing for the adequacy of complex configurations in predicting outcome scores usually includes consistency metrics and does not include statistical hypothesis testing, "tenet" is the term in-use here to express testable precepts of complexity theory in service research contexts. Testing for the statistical influence of configurations (i.e., algorithms) for accuracy in predicting high scores for an outcome condition is possible and does appear in the literature (e.g., McClelland, 1998).

\section{4a. T1: Complex demographic configurations affect customer evaluations of service facets}

The first core tenant (T1) in the GCT is that a few of the complex demographic configurations are indicators of high evaluation scores in the (a) simple and (b) collective customer evaluations of service facets. Arrow A in Figure 2 is a visual of these evaluations. The four demographics simple antecedents combine in a "truth table" (Ragin, 2008) in more than 16ways because one or more of the simple antecedent may be negative in a given antecedent and one or two of the simple antecedents may be irrelevant for a given configuration's influence on an outcome condition. For example, $\sim \mathrm{A} \bullet \mathrm{E} \bullet \mathrm{O} \bullet \sim \mathrm{G}$ is a complex configuration representing a young adult $(\sim \mathrm{A})$, high education completion $(\mathrm{E})$, high occupational status $(\mathrm{O})$ and a male $(\sim \mathrm{G}$ where G represents female gender), where sideways tilde (“ $\sim$ ”) represents negation (e.g., 1-A = $\sim A)$. If the impact is a high score on outcome $\mathrm{U}$ is about the same for $\sim \mathrm{A} \bullet \mathrm{E} \bullet \mathrm{O} \bullet \sim \mathrm{G}$ and $\mathrm{A} \bullet \sim \mathrm{E} \bullet \mathrm{O} \bullet \sim \mathrm{G}$, then simplifying the two models to $\sim \mathrm{A} \bullet \mathrm{O} \bullet \sim \mathrm{G}$ - this model indicates high scores for this model associates with high $\mathrm{U}$ scores no matter the E score. 
A truth table or "property space" (Lazarsfeld, 1937) analysis expresses all the combinations possible among the simple antecedent conditions. For four simple antecedents at three levels each (negation, absent, and positive), a total of 81 combinations are possible $\left(3^{4}=\right.$ 81). For six simple antecedent conditions having 3 levels for each, 729 combinations occur theoretically. In configural analysis of data, not all theoretically possible combinations appear among the data, especially in small sample $(\mathrm{n} \leq 30)$ studies - empty cell combinations are identified as "remainders" in configural asymmetric research.

\section{4b. T2: Causal asymmetry: demographic configurations leading to negative outcomes are} not the mirror opposites of demographic configurations leading to positive outcomes

The second core tenet (T2) in the GCT is that (a) a few of the complex demographic configurations are indicators of low evaluation scores in the (a) simple and (b) collective customer evaluations of service facets and (b) this second group of complex antecedent configurations indicating a negative outcome $(\sim \mathrm{U})$ are not mirror opposites of the first set of indicators. Thus, “causal asymmetry” (Fiss, 2011; Fiss, Marx, \& Cambré, 2013) occurs in explaining and predicting $U$ versus $\sim \mathrm{U}$. For example, occupational status $(\mathrm{O})$ may often appear in configurations accurate in explaining high scores for an outcome (U) but $\mathrm{O}$ may be irrelevant in explaining low scores for the same outcome $(\sim)$.

\section{4c. T3: Unique complex antecedent configurations are sufficient but not necessary for high scores in an outcome condition}

The third core tenet (T3) for demographics configurations: no simple antecedent condition (A, E, O, or $\mathrm{G})$ is sufficient or necessary for explaining high scores in a given service facet or overall evaluations of the service facets (an outcome $U$ for service facets). GCT 
recognizes that alternative combinations of antecedents will indicate a high score in an

outcome-more than one path exists for high scores to occur in an outcome condition. Thus, one complex configuration can be sufficient but it is not necessary for the occurrence of a high score in the outcome condition.

\section{4d. T4: Simple antecedent conditions can be necessary but they are insufficient for indicating high scores in an outcome condition}

Simple antecedent statements may be necessary but are insufficient for a high score in an outcome because several ingredients constitute a service enactment (Figure 1, panel D) - just as several ingredients are necessary in baking a delicious cake. GCT does not focus on comparing the relative size of the net effect of each simple condition in a given configural model; GCT focuses are describing, explaining, and predicting high outcome scores by complex $(2+)$ antecedent conditions.

Note that none of the tenets in the GCT refer to symmetric predictions - they do not include any predictions about low scores or high scores for an outcome when low scores occur in the complex antecedent conditions-in this aspect the GCT tenets are less restrictive than symmetric testing of hypotheses. At the same time, the GCT is more restrictive in its prediction requirement of consistently high scores in $\mathrm{U}$ by a few complex antecedent conditions - the consistency rule usually applied in configural research is that all or nearly all scores of U should be equal to or above the main diagonal of scores in an XY plot (Figure 1, panel C) where $\mathrm{X}$ is the complex configural antecedent condition and $\mathrm{Y}$ is the outcome condition ( $\mathrm{U}$ or $\sim \mathrm{U})$.

\section{4e. T5: Within different complex antecedent combinations, simple antecedent conditions may appear as a positive and negative influence on an outcome}


T5: A simple antecedent conditions is a positive indicator in some configurations and a negative indictor in other configurations on high scores in an outcome condition-whereby the outcome condition is $\mathrm{U}$ or $\sim \mathrm{U}$. For example, older customers (A) may contribute positively to high score evaluations of service facets of a beauty salon/spa; younger customers ( A) may contribute positively to high score evaluations of service facets of a beauty salon/spa. Both A and $\sim$ A may contribute negatively to high-to-low evaluation scores of service facets of a beauty salon/spa. The valence (sign) of influence of a simple antecedent depends upon what additional simple conditions constitute a given complex configuration.

This tenet (T5) in complexity theory advances beyond rational economic theory of rational consumer behavior to explain seeming anomalies. Consider the question, "Can an increase in price associate with increasing demand?" Rational economic theory predicts only a decreasing price and increasing demand relationship. Yet, empirical studies support the perspective that price increases associate with demand increases in certain contexts (Leibenstein, 1950; Milgrom and Roberts, 1986). T5 expresses the perspective that both a positive and negative influence occurs for most simple antecedent conditions-each simple condition has a positive and negative influence on an outcome depending upon the specific complex configurations in which the simple antecedents appear.

\section{4f. T6: The presence of a companion with the customer modifies how a customer evaluates service facets}

A "purchase pal" is a family member, friend, colleague from work, or an acquaintance that the customer knows beforehand or develops a friendship at the shopping site that may influence the customer's assessment and purchases while experiencing the service enactment 
(Chebat, Haj-Salem, \& Oliveira, 2012; Woodside \& Sims, 1976). Purchase pals may increase the customer's confidence to commit to service enactments (e.g., hair coloring) that s/he might otherwise postpone. Purchase pals may provide the "voice of reason" to block the customer's action to embrace a "daring do" (Hielscher, Fisher, \& Cooper, 2009). T6 expresses the perspective that the mere presence of purchase pals affects how customers assess service facets. Such a modifying influence may be a positive or negative influence depending on what other ingredients appear in specific configurations (e.g., the presence of purchase pals may occur more frequently with young customers ( A) versus older customers (A) assuming that more youthful customers are less able to rely on their own assessments of outcomes of prior service enactments than older customers).

\section{4g. T7: Beauty/spa expenditure levels modify the influence of demographic configural influences on service facets}

Customers spending relatively high levels of money for service enactments may be more vigilant in judging service facets than other customers-big spenders occupy different "money worlds" versus small spenders (cf. Tatzel, 2002). Big spenders may expect to receive hands-on service from senior versus junior staff members, the use of the best cosmetics, special pampering and seating, and speedy compliance to requests. Consequently large expenditures (L) may have a positive as well as a negative modifying influence in different demographic configuration influences on service facet evaluations.

The same may occur for the negation of large expenditures $(\sim \mathrm{L})$. The negation of big spending does not necessarily associate with the high or low scores in an outcome conditionmuch depends on the demographics of the big versus smaller spender: $\sim$ L may associate with 
one or other depending on the presence/absence of additional ingredients in the demographic configurations that do associate with low (high) scores in the outcome condition.

Configuratively, L may combine with $\sim \mathrm{O}$ (negation of occupational status) and $\sim \mathrm{E}$ (negation of education) to produce a particularly high vigilant affect; $\mathrm{L} \bullet \sim \mathrm{O} \sim \mathrm{E}$ are customers with low occupational status, low education, with high expenditures for the service-possibly for a very special occasion since such a configuration would not be expected to occur frequently.

\section{4h. Configurations of customer service-facet evaluations affect overall service outcomes and intentions toward the service provider}

T8 to T12 in the GCT application to beauty salon/spa indicate relationships among service facets and outcomes - the two center Venn diagrams in Figure 2 and arrow B. The five service facets appearing in Figure 2 include people (e.g., stylist) quality; architectural features; ambience - aroma, temperature, lighting; product displays; and background music. Sufficient number of personnel is a sixth service facet in the study but does not appear to reduce the level of complexity in Figure 2.

The selections of service facets, service outcomes, and intentions for the study are based on a literature review of both empirical positivistic studies (Babin \& Darden, 1995; Baker, Parasuraman, Grewal, \& Voss, 2002; Bitner, 1995; Bloemer \& De Ruyter, 1998; Donovan \& Rossiter, 1982; Donovan, Rossiter, Marcoolyn, \& Nesdale, 1994; Hudson \& Gilbert, 2000; Mathwick et al., 2001; Mitchell, 2001; Sharma \& Stafford, 2000) and ethnographic studies (Barber, 2008; Grimlin,1996; Otnes, Ilhan, \& Kulkarni, 2012; Sharma \& Black, 2001; Toerien \& Kitzinger, 2007; Üstüner \& Thompson, 2012) relating to service industry studies in general and the beauty salon/spa industry in particular. 
Figure 2 here.

The general theoretical perspective regarding service facets is that they serve as both outcomes and antecedent conditions. Service facets are ingredients in service enactments. Different configurations of service facets affect high scores in service outcomes. Four service outcomes appear in Figure 2: pleasure arousal; superior service quality; effective treatment; value for the money. The empirical study here also includes analyzing complex antecedent configurations indicating high scores for positive and the negation scores for each of these four outcomes.

The study includes the examination of three customer intentions toward the beauty salon/spa: intentions to return; booking additional time per session to cover additional services; and spending more money during future sessions. The study includes analyzing complex antecedent configurations indicating high scores for positive and the negation scores for each of these three intentions. Because the reasoning supporting the specific tenets regarding service facets' influence on service outcomes and due to space limitations, the remaining tenets are stated without elaboration. Using a net effects approach, prior empirical findings using symmetrical testing (i.e., multiple regression analysis) support the general perspective that specific service facets influence patient/client/customer assessments of service outcomes (e.g., Woodside, Frey, \& Daily, 1989).

T8: Complex service-facet configurations affect high scores for customer evaluations of service outcomes. T9: Causal asymmetry occurs, that is, service facet configurations leading to negative outcomes are not the mirror opposites of demographic configurations leading to positive outcomes. T10: Unique configurations of service facets are sufficient but each is not necessary 
for high-scores for service outcomes to occur. T11: Simple service-facet antecedent conditions can be necessary but are insufficient for high scores for an outcome condition. T12: Simple antecedent service facets can have a positive and negative influence on an outcome - the valence depends upon the presence of specific additional service facets in complex antecedent configurations.

Similarly, following the general framework by Woodside, Frey, and Daily (1989) of how customer evaluations of service enactments influence satisfaction and intention outcomes, configurations of service outcomes are principal indicators of customers' service intentions. Arrow $\mathrm{C}$ in Figure 2 is a visual of this perspective and the five final tenets in the complexity theory of beauty salon/spa services. T13: Complex service-outcome configurations affect high scores for customer intentions relating to the service provider. T14: Causal asymmetry occurs, that is, service outcome configurations leading to low intention scores are not the mirror opposites of outcome configurations leading to high intention scores. T15: Unique configurations of service outcomes are sufficient but each is not necessary for high-scores for service intentions to occur. T16: Simple service-outcome antecedent conditions can be necessary but are insufficient for high scores for an intention condition. T17: Simple serviceoutcome antecedents can have both a positive and negative influence on intentions-which depends upon what other simple conditions make-up the complex configurations indicating high scores in the outcome condition.

\section{Method}

The present study includes an empirical examination of the 17 complexity tenets in the context of evaluations by customers of a large beauty salon/spa located in Changhua City. 
(Changhua City is located in Changhua County, west-central Taiwan. The county has a population of 1.3 million inhabits - the second largest county by population in Taiwan.) The specific beauty salon/spa has 28 full-time employees including 11 front-line professionals, 6 junior staff personnel and trainees; 5 immediate supervisors, 3 senior supervisors, and 2 ownerexecutives. The owners requested anonymity of the name of the salon/spa in this research.

A quota convenience sample of customers was asked to complete a survey on-site after receiving and paying for a service experience. The quota was based on coverage of age and gender segments of the salon/spa so that the sampled respondents matched the salon/spa's population share of young $(<30)$, middle-aged $(30-50)$, and older $(>50)$ customers and its ratio of female to male customers. The survey was completed by samples representative of five age groups by both genders. The survey was completed anonymously by each respondent. Each respondent was urged to be open and forthcoming in answering. A small gift was given to each respondent for participating in the study.

\section{5a. Survey Instrument}

Along with the demographic questions, customers were asked a total of 31 assessment questions and 4 buying intention questions. Most respondents completed the survey in less than five minutes. The intention for the study was that the constructs would include multiple-item

five-point scales (very poor to very good and very much disagree to very much agree; this goal was achieved with high Cronbach alpha's and clear rotated factor structures for nearly all constructs).

The survey comprises five parts including store environment, experiential value, store image, buying intention, and socio-demographic items. Prior studies informed the development 
these items. The store environment part of the questions comprised 15 questions that can be allocated in three sub-categories namely social, ambience, and design (Baker, Parasuraman, Grewal, \& Voss, 2002). Experiential value aspects of questions were designed based on the work of Mathwick et al. (2001), which further divide into four dimensions, namely customer return on investment (ROI), aesthetics, playfulness, and service excellence.

The store image items were designed based on prior research (Mitchell, 2001). The study incorporated items from prior studies in four sub-categories of store image--namely product, facility, service, and price images--to include twelve questions. The buying intention measure comprised four questions based on works regarding customer loyalty (Hudson \& Gilbert, 2000). The above questions are in 5-point Likert scales where 1 denotes strongly disagree and 5, strongly agree. The final part of the questionnaire includes respondents' socio-demographic information, such as age, gender, marital status, education level, occupation, and yearly salary.

The assessment survey items in the survey appear in Appendix 1. Summaries of the quartimax-rotated factor structures for most of the individual items in the survey appear in Tables 1 and 2 in the Appendix 2. The factor structures for the items for constructs in the scale support the conclusion that constructs are distinct and usefully describe specific service facets, outcomes, and intentions. Cronbach alpha is above 0.70 for each of the multi-item constructs for service facets and outcomes.

\section{5b. Respondents}

A total of 436 customers responded to the survey; the response rate was $75 \%$ of customers asked to participant. "No time, sorry," was the principal reason offered for not agreeing to participate. The majority of the respondents were female $(n=383,88 \%)$. In terms of 
age groups, only 16 respondents were less than 21 years old, which is reasonable since young respondents may not be able to afford the service; $32 \%$ of the respondents were between 21 to 30 years old, $29 \%$ between 31 to 40 years old, $22 \%$ between 41 to 50 years old, and $13 \%$ were 51 or older. A total of 147 respondents reported having a university degree (34\%), followed by high school equivalent education $(n=138,32 \%)$, and technical college $(n=94,22 \%)$. Very few respondents reported having secondary school, primary school, or post-graduate degrees. In terms of occupation, 139 respondents (32\%) worked in service industries, 64 worked as business managers (15\%), 56 were full-time housekeepers (13\%), and 44 were freelancers (10\%). Very few respondents were retired, industrial workers, or farmers.

The beauty salon/spa is a relative luxury service in Taiwan, which means only adult respondents with sufficiently high incomes may afford the service. Indeed, only 232 respondents $(53 \%)$ reporting spending more than NT\$ 1500 per visit $(1.00 \mathrm{NT} \$=0.033 \mathrm{USD}$ in 2014$)$. Only 118 respondents $(27 \%)$ report spending more than NT\$1000. Since spa is an intimate experience, more than half $(n=239,55 \%)$ of the respondents visited by themselves. Others visit with friends $(n=77,18 \%)$ or family members $(n=72,16 \%)$. Only 37 respondents went with colleagues $(9 \%)$.

\section{Findings}

To learn what variable associations indicate by a conventional data analysis perspective, some preliminary symmetrical testing was done. Correlations and cross-tabulations were run to examine the associations among the four principal sets of constructs: demographics, customer assessments of service facets, service outcome assessments, and customers' intentions toward the service provider. Following this preliminary analysis, asymmetrical fsQCA data analyses were 
performed to examine major tenets of complexity theory. This section first reports on the findings for the symmetrical tests followed by the findings for the configural asymmetric tests.

\section{6a. Correlation and Cross-Tabulation Findings}

Tables 1-3 provide collections for socioeconomic variables, customer service-facet assessments, service outcome assessments, and intentions. From Table 1, a meta-analysis for the thirty correlations for the socioeconomic and service-facet assessments results in an average $\mathrm{r}=$ .032 with an estimated range of 0.016 to 0.049 - thus indicating a statistically significant small effect size. These findings support Bass, Tigert, and Lonsdale's (1968) observations that symmetric tests indicate minor relationships among socioeconomic and dependent customerrelated variables — while other data analysis methods indicate major relationships among these same variables.

Tables 1 here.

Table 1 includes the highly significant correlations among the service facets which would result in multi-collinearity problems in regression analyses. However, these correlations are all below 0.70 and sufficiently low to conclude that each construct is measure a unique service facet.

Tables 2 and 3 here.

The 25 correlations for the socioeconomic variables and customer evaluations of service outcome and intentions in Table 2 include 23 non-significant findings with the correlations ranging from - -139 to +.102 - again supporting the conclusion that symmetric test findings have 
zero to small effects on customer assessments. Table 2 correlations among service facet constructs and with service intentions are significant statistically and medium in effect sizes.

Table 3 includes correlations among service facets and intentions. As expected, the correlation among the two intention constructions - spend more money on next visit and intention to return, is the highest correlation within Tables 2 and $3(r=.647)$. The findings in Table 3 indicate medium effect sizes among service facets and intentions - about at the same levels as the correlations among service outcomes and intentions. Such findings support the conclusion that dotted arrow f should be replaced by a solid arrow having the same emphasis as arrow B in Figure 1.

Table 4 here.

Table 4 provides correlations for service facet evaluations, service outcomes, and intentions. The "quick clustering" (Kamen, 1970) at the bottom of Table 4 shows the largest correlations; these appear on double-headed arrows - the purpose of quick clustering is to visualize the findings to ease interpretation. The main conclusion is that the three categories of customer judgments associate significantly. Customer outcome evaluations of service quality delivered appears to be a central linkage between service facet evaluations, other service outcomes, and intention measures.

Table 5 here.

Tables 5 and 6 present examples of the presence of contrarian cases. Table 5 is a cross of two service outcome evaluations: effective treatment and service quality delivered. On a variable by variable basis, the $\mathrm{phi}^{2}$ measure indicates a positive large effect size (Cohen, 1977). A substantial majority of cases with positive evaluations about receiving effective treatment give 
positive evaluations about the delivered overall service quality; similarly, a substantial majority of cases with negative evaluations about effective treatment have negative evaluations about delivered service quality. However, both negative and positive contrarian cases do occur. A total of 41 negative and 12 positive contrarian cases occur. The findings include two cases with highly negative effective treatment evaluations and highly positive service quality evaluations. The findings include one case with highly positive effective-treatment evaluation and a highly negative evaluation for delivered service quality. Rather than ignore such cases in reports only on a positive main effect, fuzzy-set qualitative comparative analysis (fsQCA) models both positive and negative routes to high scores in an outcome condition.

Table 6 here.

Table 6 demonstrates the occurrence of both negative and positive contrarian cases for a service outcome (customer evaluations of delivered service quality) and intention to return to the service provider. The numbers of negative and positive contrarian cases are nearly identical. Note in Table 6 that the $\mathrm{phi}^{2}$ indicates a large effect size; yet, contrarian cases occur. What combination of antecedent conditions includes negative contrarian cases that indicate highly positive outcome scores? What combination of antecedent conditions includes positive contrarian cases that indicate high scores in the negation of the outcome condition? (A negation outcome condition is equal to one minus the calibrated outcome score; the next section describes calibrating scores in fuzzy-set QCA.)

\section{6b. Calibration}

The use Boolean algebra in the study of the influence of complex configurations of antecedent conditions requires transforming original scaled values to fuzzy set values for both 
antecedent and outcome conditions. All fuzzy set values for all simple conditions range from 0.00 to 1.00 and these values indicate the degree of membership of the case in each condition. The set membership scores that result from calibrating original scores into fuzzy set scores are not probabilities, but instead are transformations of ordinal or interval scales into degree of membership in the target set. "In essence, a fuzzy membership score attaches a truth value, not a probability, to a statement (for example, the statement that a country is in the set of development countries)" (Ragin, 2008, p.183).

Ragin (2008) emphasizes that fuzzy sets, unlike conventional variables, must be calibrated. "Because they must be calibrated, they are superior in many respects to conventional measures, as they are used in both quantitative and qualitative social science. In essence, I argue that fuzzy sets offer a middle path between quantitative and qualitative measurement. However, this middle path is not a compromise between the two; rather, it transcends many of the limitations of both" (Ragin, 2008, p. 174).

Much of variation captured by ratio-scale indicators such as age and income is simply irrelevant to the distinction by low and high values. The original values must be adjusted on the basis of accumulated substantive knowledge in order to be able to interpret low versus high scores in a way that resonates appropriately with existing theory (cf. Ragin, 2008, p. 18). Ragin points out that there is a world of difference between living in a country with a gross national product (GNP) per capita of $\$ 2000$ and living in one with a GNP per capita of $\$ 1000$; however, there is virtually no difference between living in one with a GNP per capita of $\$ 22,000$ and living in one with a GNP per capita of $\$ 21,000$. Calibration of fuzzy-set measures addresses such issues directly. 
Fuzzy-set calibration makes use of external information on the degree to which cases satisfy membership criteria and not inductively derived determination (e.g., using sample means). Criteria need to be set for three breakpoints in fuzzy-set calibration with endpoints of 0.00 for full non-membership to 1.00 for full membership. The breakpoints include 0.05 for threshold for full non-membership, 0.50 for the crossover point of maximum membership ambiguity; and 0.95 for the threshold of full membership. Determination of the three breakpoints permits calibration of all original values into membership values using a direct method and an indirect method (see Ragin, 2008). Similar to the mathematics involved in calculating partial standardized regression coefficients for variables in MRA using the Statistical Packages for the Social Sciences (SPSS), performance of the mathematical calculations to calibrate all membership scores for a simple condition can be done by using a software routine in the program, www.fs/QCA. See Ragin (2008, pp. 104-105) for an example of using this procedure.

The original values in 5-point Likert scale can be calibrated so that $1=0.05 ; 2=0.25 ; 3=$ $0.50 ; 4=0.75 ; 5=0.95$. This procedure was done in the study here. However, if respondents scores ignore an extreme score such as 1 or 5 on a Likert scale, the calibration scores would have been adjusted accordingly; for example, if one or two respondents among 100+ respondents provided a strongly disagree response (score of "1") among several Likert items, then the calibration would have been $1=0.00 ; 2=0.05 ; 3=0.33 ; 4=0.67 ; 5=0.95$.

\section{6c. Index Metrics for Measuring Consistency and Coverage of a Complex Configuration}

The consistency index gauges the degree to which the cases share a simple or complex condition in displaying the outcome in question - consistency is analogous to a correlation in 
statistical analysis. The coverage index in fsQCA assesses the degree to which a simple and complex causal condition (recipe) "accounts for" instances of an outcome condition-coverage is analogous to a $\mathrm{r}^{2}$ in statistical analysis. In QCA a consistency index above 0.80 with a coverage index of 0.45 indicates high membership scores in the outcome condition for nearly all high scores in the antecedent statement and a substantial share of the cases fitting an asymmetric sufficiency distribution. Consistency $(\mathbf{X i} \leq \mathbf{Y i})=\sum\{\min (\mathbf{X i}, \mathbf{Y i})\} / \sum(\mathbf{X i})$ where $\mathrm{Xi}$ is case i's membership score in set $\mathbf{X}$; Yi is case i's membership score in the outcome condition, $\mathbf{Y}$; $(\mathbf{X i} \leq$ Yi) is the subset relation in question; and "min" dictates selecting the lower of the two scores. Coverage $(\mathbf{X i} \leq \mathbf{Y i})=\sum\{\min (\mathbf{X i}, \mathbf{Y i})\} / \sum(\mathbf{Y i})$. The formula for coverage of $\mathrm{Y}$ by $\mathrm{X}$ substitutes $\sum$ (Yi) for $\sum(\mathrm{Xi})$ in the denominator of the formula for consistency. See Ragin (2008) and Woodside (2013a, 2013b) for elaborations and numerical examples.

Due to substantial space requirements necessary to fully describe the method, this section only provides an introduction to the theory and use of QCA. Ragin (2008) provides an extensive description of theory and method of QCA; a user's manual and software for QCA is available at www.fsQCA.com. QCA studies cases as configurations of causes and conditions rather treating each independent variable in a given analysis as analytically distinct and separate as done in conventional quantitative methods. "The key difference between the two is captured in the idea of a causal 'recipe' - a specific combination of causally relevant ingredients linked to an outcome. In set-theoretic work, the idea of a causal recipe is straightforward, for the notion of combined causes is directly captured by the principle of set intersection” (Ragin, 2008, p. 9).

\section{6d. T1: Receives Support-Complex demographic configurations do indicate customer evaluations of service facets.}


The findings in Table 7 support T1. Four models with complex antecedent conditions that include various demographic characteristics along with companionship and expenditure levels indicate high scores in the outcome condition for customer evaluations of people quality. Note in Table 7 that the first model has a consistency index equal to 0.941 and a unique coverage index equal to 0.026 . The model includes six ingredients - customers visiting without a companion who are housekeepers, not service workers, who are females with low education, and they are young.

$\sim$ companion $\sim \sim$ servicew $\bullet$ housekeeper $\bullet$ female $\bullet$ edu $\bullet \sim$ age $\leq$ people quality

The XY plot of model 3 appears at the bottom of Table 7. Each dot in the XY plot represents one or more cases (i.e., customers) in the study—-some customers have the same scores in the plot. Note that the low scores for model 3 associate with low and high scores for the outcome, people quality evaluations. Model 3 predicts only that high scores in the complex statement indicate high scores in the outcome condition.

Table 7 here.

Note in Table 7 that the negation of companion (i.e., no companion appears in three of the four models). Model 4 in Table 7 represents older female service workers with high education, high expenditure, with a companion in tow. The models in Table 7 indicate that the impacts of the simple antecedent conditions are not always positive or negative or even always present. Life_-including evaluations of service experiences and outcomes — is too complex to be captured by reports of main effects and net effects.

Spa expenditures need not be high for high people quality evaluations by customers. High spa expenditures appear in two of the four models in Table 7 and the negation of spa 
expenditures appears in one of the models. Spa expenditures are excluded from model 1 in Table

7. Such findings support basic tenets of complexity theory-both a simple antecedent condition can have a positive, negative, and no relationship with an outcome conditions depending on the conditional statement (i.e., recipe) of complex antecedent conditions associating with high scores in a particular outcome condition. Due to space limitations, findings for the associations of other demographic $\bullet$ companion•expenditure models for service facet evaluations other than people quality do not appear here but these additional findings support T1 as well.

Additional findings also support T1 for a complex demographic, companion, and expenditure condition indicating high overall scores for all service facets $($ i.e., $P \cdot R \cdot L \cdot D \cdot B$ for service facets in Figure 1). The top portion of Table 8 reports the specific complex model for this compound outcome condition. This model indicates that a young female with low education who is a housekeeper spending few funds and visiting alone to have high scores for overall service facets. Note that the $\mathrm{Y}$ in a model can be a compound statement or two or more conditions rather than a statement of a simple outcome condition.

Table 8 here.

\section{6e. T2: Receives Support—causal asymmetry occurs—demographic antecedent configurations leading to negative outcomes are not the mirror opposites of demographic configurations leading to positive outcomes}

The findings in Tables 9a and 9b support T2. The outcomes for these models are return intentions. Table 9a predicts high scores in return intentions using demographics and service outcome evaluations as indicators. Table $9 \mathrm{~b}$ predicts high scores in the negation of return intentions; Table 9b answers the question what service outcomes drives which customers away.. 
Both Tables 9a and 9b include unique complex antecedent conditions which include demographic, companion, expenditure level, and service outcome conditions. Notice that in both intentions to return and the negation of returning include age and $\sim$ age, as well as female and $\sim$ female, as well as education and education. Consequently, the focus on main effects of age, gender, and education is misplaced if the objective is to identify which customers are likely to return and which are likely not to return. At first blush while the findings in Tables $9 \mathrm{a}$ and $9 \mathrm{~b}$ appear to be overly complex, such customer recipes are easy to process by service workers and managers.

Tables 9a and 9b here.

Note that the negation of service-quality evaluation appears in two of the models, positive service-quality evaluations appear in 16 models in Table 9a, and service-quality evaluation does not appear in three of the models. None of the models in Table 9a include both the negation of service quality and the negative of effective treatment evaluations. All the models in Table 9bthe negation of return intentions - includes either the negation of service quality or the negation of effective treatment or both evaluations.

\section{6f. T3: Receives Support-unique complex antecedent configurations are sufficient but not necessary for high scores in an outcome condition}

With the exception of finding only one model is consistent in predicting high scores for overall service facet evaluations (top of Table 8), T3 receives support. Several complex antecedent conditions are sufficient for predicting high scores for each of the unique service facets, the service outcomes, and the intention conditions. Note the Table $8 \mathrm{~b}$ includes three complex service-facet models predicting high scores for overall service outcomes. Table 8c 
includes two service outcome models predicting high scores for overall intentions toward the service provider.

\section{6g. T4: Receives Support—simple antecedent conditions can be necessary but they are insufficient for indicating high scores in an outcome condition}

Figure 3 is an example of a service facet support T4. Having a sufficient number of professional service providers is a necessary condition that is insufficient for high overall outcome scores. Notice in Figure 3 that all scores for overall outcome scores are relatively low when scores are low for this antecedent condition. When scores are high for the number of people sufficient scores, the overall outcome scores are high and low-Figure 3 is most similar to Figure 1, panel D. Failing to provide sufficient numbers of professional service providers can hurt but doing so is not sufficient for high scores in the overall outcome following the service enactment/experience.

Figure 3 here.

\section{6h. T5: Receives Support—within different complex antecedent combinations, simple antecedent conditions may appear as a positive and negative influence on an outcome}

Nearly all the models in all the tables support T5. Thus, contrarian cases occur in datasuch cases show that high $\mathrm{X}$ indicates high $\mathrm{Y}$, low $\mathrm{Y}$, and not anything about $\mathrm{Y}$. The negation of $\mathrm{X}$ indicates high $\mathrm{Y}$, low $\mathrm{Y}$, and not anything about $\mathrm{Y}$. Which of these three relationships occur for the outcome and the negation of the outcome depends upon what other simple antecedent condition co-join with $\mathrm{X}$. The bottom-line is that the focus on the net effect of $\mathrm{X}$ on $\mathrm{Y}$ typically offers a meager explanation versus the sophisticated and useful explanations that complex antecedent conditions provide. 


\section{6i. T6: Receives Support— the presence of a companion with the customer modifies how a customer evaluates service facets}

The findings in Tables 7 and 8 support T6. The presence and absence of a companion within complex antecedent conditions contributes to high scores for people quality assessments and overall service facet quality - and this contribution appears consistently in the configural models. These findings fit well inside Shakespeare's As You Like It monologue by the melancholy Jaques in Act II Scene VII, “All the world is a stage” as well as Goffman's (1959) Presentation of Self in Everyday Life.

What may be surprising is that for the majority of models the absence rather than the presence of a companion contributes to increases in specific and general service facet evaluations. Note that next to the top of Table 8 that four of the six negation models for overall service facet evaluation includes the presence of a companion. Possibly customers may transform into critiques as well as actors in the presence of companions but identify more often with the service provider when companions are absent. Whatever the process, the absence/presence of companions influences customer assessments of service facets consistently.

\section{6j. T7 Receives Support—beauty/spa expenditure levels modify the influence of demographic configural influences on service facets}

Both high and low customers' beauty/spa expenditure levels contribute positively to customers' service facet evaluations_- which depends upon what additional ingredients are included in the alternative complex-antecedent configurations. Spending more versus less money does not equate consistently to higher or lower customer service-facet evaluations. What 
appears to receive support is that service providers need to insure that appropriate care in crafting service facets is presented that complement the expenditures customers make.

\section{6k. Configurations of customer service-facet evaluations do influence overall service outcomes and intentions toward the service provider}

T8 receives support: complex service-facet configurations affect high scores for customer evaluations of service outcomes. Table $8 \mathrm{~b}$ includes three models of complex service-facet antecedents and service outcomes. T9 receives support: unique configurations of service facets are sufficient but each is not necessary for high-scores for service outcomes to occur. Table $8 \mathrm{~b}$ includes three models that are very high in consistency in predicting high scores for service outcomes. T10 receives support: simple service-facet antecedent conditions can be necessary but are insufficient for high scores for an outcome condition. Tables 10a and 10b provide details. T11: Simple antecedent service facets can have a positive and negative influence on an outcome - the valence depends upon the presence of specific additional service facets in complex antecedent configurations. Tables 10a through $10 \mathrm{~d}$ include antecedent service-facet evaluations affecting the four service outcomes. Note that the valences of specific service facets vary within the different complex antecedent conditions.

Tables 10a and $10 \mathrm{~b}$ here.

T12 receives support: complex service-outcome configurations affect high scores for customer intentions relating to the service provider. Table $8 \mathrm{c}$ includes two specific models with high consistency for the relationship for service-outcome configurations and customer intentions. The bottom of Figure 4 shows that value for the money alone is sufficient (but not necessary) for high intentions to return. Figure 4 is a summary visual of key findings in the study. 
Figure 4 here.

T13: Causal asymmetry occurs, that is, service outcome configurations leading to low intention scores are not the mirror opposites of outcome configurations leading to high intention scores. Two models indicate consistent high scores in outcome conditions and the negation of returning to the service provider:

$\sim$ service_quality $\sim$ pleasure_arousal $\sim$ not_value_money $\leq$ not_return $(4, \mathrm{C} 1=.83, \mathrm{C} 2=.50)$

effective_treatment $\sim$ service_quality $\sim$ pleasure arousal $\leq$ not_return $(5, \mathrm{C} 1=.79, \mathrm{C} 2=.32)$

where $\mathrm{C} 1=$ consistency and $\mathrm{C} 2=$ raw coverage. Note that the failure to provide pleasure arousal enters both models 4 and 5-failure to provide pleasure arousal is necessary but not sufficient in these models to indicate the negative of returning. Table 9c provides unique service outcome models predicting the negation of overall intentions that are not the mirror opposites of the models for overall intentions that appear in Table 8c.

T14 receives support: Unique configurations of service outcomes are sufficient but each is not necessary for high-scores for service intentions to occur. T15: Simple service-outcome antecedents can have both a positive and negative influence on intentions - which depends upon what other simple conditions make-up the complex configurations indicating high scores in the outcome condition. See Table 9c for specific findings.

\section{XY Plot for High Consistency for Service Facets and Intentions to Return}

Figure 5 is an $\mathrm{XY}$ plot showing high consistency for a service facet model and intentions to return. The model show that high scores on the complex antecedent condition that includes architecture, sufficient service personnel, and product displays indicate high scores on intentions 
to return. While informative, this model is only one of several service facet models that support the presence of consistent models for dotted arrow f in Figure 2.

Figure 5 here.

The findings in Figure 5 are amenable to statistical testing as well. The finding that 125 of 130 cases with high scores for the complex antecedent condition is statistically significant ( $p$ $<.001)$.

\section{6m. Support for Demographic Algorithms Indicating High Outcome Scores}

Complex antecedent demographic models alone do indicate high scores for outcome conditions as well as the negation of outcome conditions. Details appear in Tables 11a and 11b. Professional working males with high education offer high scores for service outcomes and do across a range of service outcomes; see Table 11a. Older males with low education offer high scores for not pleasure arousal and not effective treatment; see Table $11 \mathrm{~b}$.

Tables 11a and Table 11b here.

\section{Contributions to Theory and Service Management Practice}

Complexity theory includes the recognition that no simple condition is the cause of an outcome of interest. Several indicators act in combination to cause an outcome of interest. Algorithm building and testing procedures such as fsQCA focus on testing combinatory theories as indicators of an outcome of interest. Both complexity theory and fsQCA do not build and test models for both positive and negative outcome of interest - both theory and method are asymmetric in focus. Unlike attempting to build useful models in predicting both high and low scores, complexity theory and fsQCA are "positive" only in focus. "You tested positive for 
cancer $(\mathrm{C})$," and "The tests indicate that you do not have cancer," are both asymmetric statements; both statements test using complex antecedent conditions which examine for $\mathrm{C}$ and $\sim$ C outcomes.

Symmetric tests and symmetric based theories attempt to do too much and too little. Too much: they attempt to build models to accurately predict both low and high scores. Given that positive behavior is not the mirror opposite of negative behavior, such attempts are doomed except for analysis of the reliability of items in a multi-item scale. Too little: symmetric theories and testing usually ignore contrarian cases; both negative and positive contrarian cases occur in medium to large data sets. Negative contrarian cases are cases with a negative antecedent condition for most cases having a positive outcome condition for a simple antecedent condition; the particular antecedent condition alone usually is neither sufficient nor necessary of the occurrence of the positive outcome. Both the negative contrarian case and the positive cases for the simple antecedent condition are ingredients in different complex antecedent conditions which are indicators for the positive outcome. A positive contrarian case is a case having a negative antecedent score associated with the given antecedent condition that has a positive outcome, yet this positive contrarian case does not have a negative outcome. Both the positive contrarian case and the cases with values supportive of the observed main effect are relevant to different complex models.

Herbert Simon (2009) informs in his chapter in Simplicity, Inference and Modelling to the beauty in "finding pattern, especially simple pattern, in the midst of apparent complexity and disorder." Simon construes parsimony itself as "pattern in the phenomena" and places it "at the root of what we mean by a scientific law.” Distinguishing between simplicity and parsimony, Simon does not think we should seek "the absolutely simplest law," but "the law that is simplest 
in relation to the range of phenomena it explains, that is most parsimonious." Simon (2009, p. 32) refers to the following statement as one of Popper's (1961) dictums, "Science seeks parsimony, not simplicity searching for pattern in phenomena."

While at first blush the empirical complex antecedent configurations appearing in the present study may not appear to be parsimonious, they are parsimonious patterns of indicators leading to outcomes of interest. Theory and research focusing on "parsimonious patterns of asymmetric outcomes of interest" is a statement taking us far beyond the dominant logic in service research and services marketing appearing in the servicescape and "servqual" literature (e.g., Harris \& Ezeh, 2008; Wakefield \& Blodgett, 1996; Zeithaml, Berry, \& Parasuraman, 1996). The asymmetric focus on building parsimonious patterns which accurately predict high scores in an outcome of interest (including negation outcomes) should complement ("replace" may apply here) the focus on net effects, that is, the dominating present focus on whether or not simple antecedent conditions and dependent variables relate to each other statistically significantly.

The issue of whether or not net effects relate significantly or not does not relate sufficiently to the principal aims of science or service management practice. Service delivery includes the alternative performance confluences of several service facets. A service facet performance is a pattern of behavior in a given context that involves one or more service providers and a customer alone one or more attending companions. Both the parsimonious customer patterns (e.g., demographic profiles) and enactments of service-facet patterns join together to influence service outcomes and all three may join together to influence customer service intentions. The Venn diagrams in Figure 2 better represent reality than the boxes and arrows diagrams in the servicescape and servqual literature because the Venn diagrams visualize 
several tenets in complexity theory. Multiple patterns occur (equifinality occurs); while one pattern may be sufficient it is not necessary for an outcome of interest to occur; contrarian cases occur and result in alternative patterns leading the same outcome as non-contrarian cases; negation models are not the mirror opposites of positive outcome models (causal asymmetry occurs).

\section{Limitations, Suggestions for Future Research, and General Conclusion}

\section{8a. Limitations and Suggestions for Future Research}

This study may be the first to formally examine tenets of complexity theory in service research contexts. However, additional studies (Chang, Tseng, \& Woodside, 2013; Woodside, 2013b, Woodside \& Zhang, 2012) are available in the service research literature that examine complex antecedent conditions as indicators of positive service outcomes. Yet, the number of studies is scant. Additional studies in additional contexts are necessary to support the usefulness of the complexity theory and complex configural analysis.

McClelland (1998) and Gigerenzer and Brighton (2009) emphasize that a critical validation question is whether or not a model (MRA and/or an fsQCA model) predicts a dependent variable (outcome condition) in additional samples-holdout samples that are separate data sets from the data set used to test the fit of data to theory. "Achieving a good fit to observations does not necessarily mean we have found a good model, and choosing the model with the best fit is likely to result in poor predictions," Gigerenzer and Brighton (2009, p. 114) observe. Unfortunately, only a handful of studies report on predictive validity, nearly all studies report only on fit validity (cf. Roberts \& Pashler, 2000). Up until this section, the study here suffers from this unnecessary limitation. 
Table 12 here.

To test for predictive validity, the sample was split into a modelling subsample and a holdout sample. Table 12 includes a predictive validation of the model 1 that appears in the table. In Table 12 the patterns of complex antecedents conditions are consistent indicators of high scores in service outcome, arouse pleasure, using the first half of cases in the sample of 435 cases. The findings for testing model 1 predictions on the data in the second sample appear below Table 12 . The findings indicate a highly consistent model $(\mathrm{C} 1=0.923)$ and high coverage $(\mathrm{C} 2=0.597)$. Additional predictive test findings support the conclusion that the highly consistent models for subsample 1 have high predictive abilities for subsample 2 and vice versa (available upon request).

\section{8b. General Conclusion}

The bringing together of complexity theory, fsQCA, and pattern research in service dominant logic is a fit-like-a-glove union for advancing theory, method, and practice in service research. Complexity theory is a useful lens for seeing that simple antecedent conditions relate to an outcome condition of interest positively, negatively, and not at all —which of these three relationships occur depends on the observed complex antecedent conditions in which the simple antecedent conditions occur. Individual service facets in service performances with successful service outcomes do not have to be all positive ingredients in all possible complex but parsimonious patterns. 


\section{Appendix 1 Survey Items}

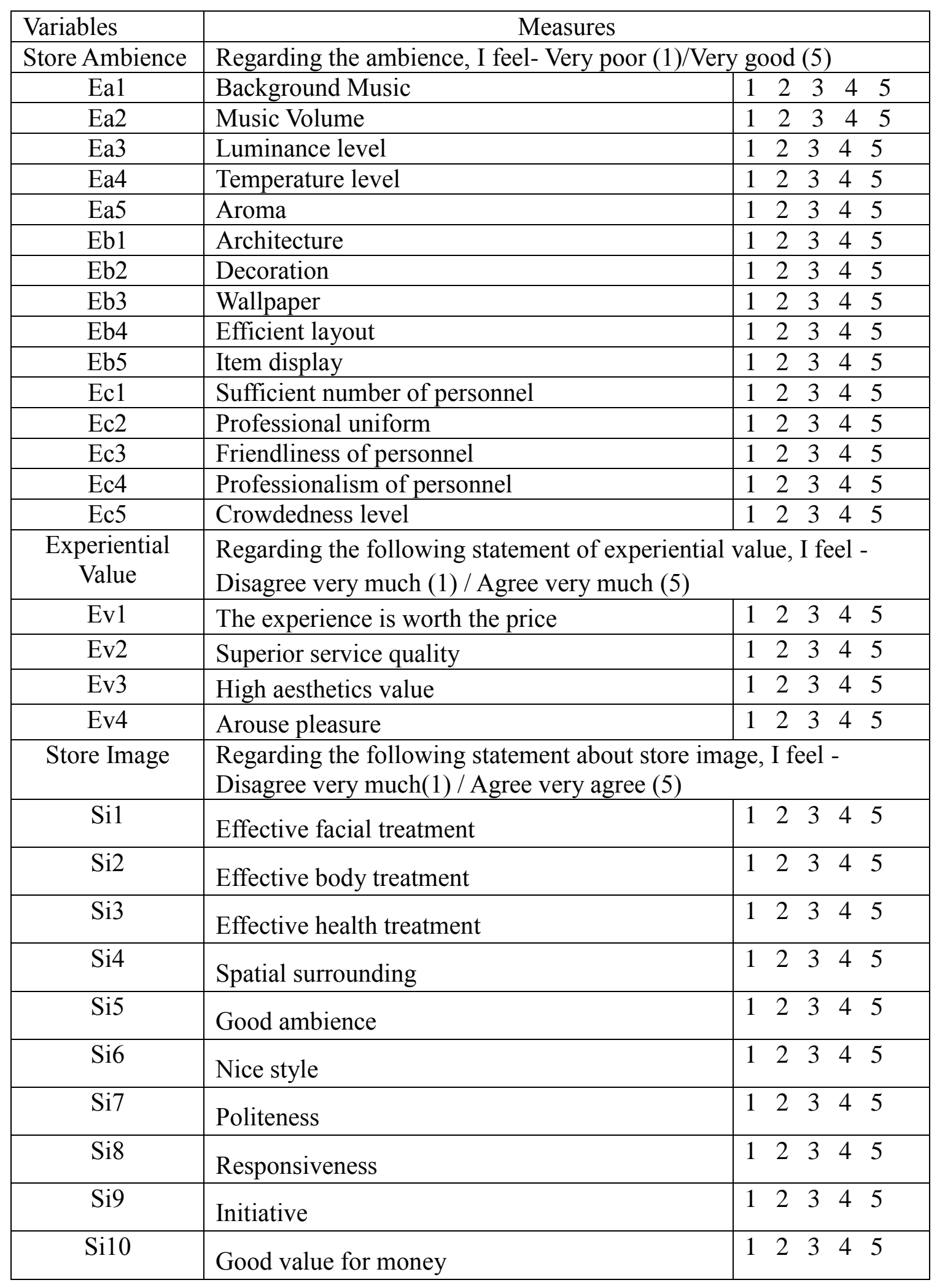




\begin{tabular}{|c|c|c|}
\hline Sil1 & $\begin{array}{l}\text { Acceptable price range for the consumption level } \\
\text { of local community }\end{array}$ & $\begin{array}{lllll}1 & 2 & 3 & 4 & 5\end{array}$ \\
\hline Si12 & Acceptable price range for me & 122345 \\
\hline $\begin{array}{l}\text { Buying } \\
\text { Intention }\end{array}$ & \multicolumn{2}{|c|}{$\begin{array}{l}\text { Regarding the following statement about buying intention, I feel - } \\
\text { Disagree very much(1) / Agree very much (5) }\end{array}$} \\
\hline & I will visit again & $\begin{array}{lllll}1 & 2 & 3 & 4 & 5\end{array}$ \\
\hline & This will be my first choice & $\begin{array}{lllll}1 & 2 & 3 & 4 & 5\end{array}$ \\
\hline & I will spend more time here & 1223455 \\
\hline & I will purchase more service here & $\begin{array}{lllll}1 & 2 & 3 & 4 & 5\end{array}$ \\
\hline
\end{tabular}




\section{References}

Babin, B. J., \& Darden, W. R. (1995). Consumer self-regulation in a retail environment. Journal of Retailing, 71(1), 47-70.

Baker, J., Parasuraman, A., Grewal, D., \& Voss, G. B. (2002). The influence of multiple store environment cues on perceived merchandise value and patronage intentions. Journal of Marketing, 66 (2), 120-141.

Barber, K. (2008), The Well-Coiffed Man: Class, Race, and Heterosexual Masculinity in the Hair Salon. Gender and Society, 22 (4), 455-476.

Bass, F.M., Tigert, D.J., \& Lonsdale, R.T., (1968). Market segmentation: Group versus individual behavior. Journal of Marketing Research, 5 (3), 264-270.

Beauty Salon Business Overview \& Trends (2012). http://www.sbdcnet.org/small-businessresearch-reports/beauty-salon-2012.

Because it's no longer worth it (2014). The Economist, January $11^{\text {th }}, 57$.

Big Five Statistics (2013). http://www.experienceispa.com/media/facts-stats/.

Bitner, M. J. (1995). Building service relationships: it's all about promises. Journal of the Academy of Marketing Science, 23(4), 246-251.

Bloemer, J., \& De Ruyter, K. (1998). On the relationship between store image, store satisfaction and store loyalty. European Journal of Marketing, 32 (5/6), 499-513.

Chang, C-W, Tseng, T-H, \& Woodside, A.G. (2013). Configural algorithms of patient loyalty. Journal of Services Marketing, 27 (2), 91-103. 
Chebat, J,-C., Haj-Salem, N., \& Oliveira, S. (2012). Three psychological processes explaining the impact of the shopping pal on mall shoppers. The 12th International Research Conference in Service Management., A Londe les Maures, France, May 29, 30, 31 \& June 1, 2012, http://www.cerog.org/lalondeCB/SM/2012_lalonde_seminar/papers/06P125-2012-CHEBAT-HAJ-SALEM-OLIVEIRA-REV-20-03-2012.pdf.

Cohen, J. (1977). Statistical power analysis for the behavioral sciences. New York: Academic Press.

Donovan, R. J., \& Rossiter, J. R. (1982). Store atmosphere: an environmental psychology approach. Journal of Retailing, 58(1), 34-57.

Donovan, R. J., Rossiter, J. R., Marcoolyn, G., \& Nesdale, A. (1994). Store atmosphere and purchasing behavior. Journal of Retailing, 70(3), 283-294.

Fiss, P. C. (2011). Building better casual theories: A fuzzy set approach to typologies in organizational research. Academy of Management Journal, 54 (2), 393-420.

Fiss, P. C., Marx, A., \& Cambré, B. (2013). Configurational Theory and Methods in Organizational Research: Introduction. In Fiss, P. C., Cambré, B., and Marx, A. (Eds.), Configurational theory and methods in organizational research (pp. 1-22, Research in the sociology of organizations, 38). Bingley, UK: Emerald.

Gigerenzer, G. (1991). From tools to theories: A heuristic of discovery in cognitive psychology. Psychological Review, 98, 254-267.

Gigerenzer, G., \& Brighton, H. (2009). Homo heuristics: Why biased minds make better inferences. Topics in Cognitive Science, 1, 107-143. 
Gladwell, M. (2002). The tipping point. New York: Little, Brown.

Goffman, E. (1959). The presentation of self in everyday life. New York: Anchor.

Grimlin, D. (1996). Pamela's Place: Power and Negotiation in the Hair Salon. Gender and Society, 10(5), 505-526.

Harris, L.C., \& Ezeh, C. (2008). Servicescape and loyalty intentions: an empirical investigation. European Journal of Marketing, 42 (3/4), 390-422.

Hielscher, S., Fisher, T., \& Cooper, T. (2009). The return of the beehives, Brylcreem and botanical! An historical review of hair care practices with a view to opportunities for sustainable Design. In: Undisciplined! Design Research Society Conference 2008, Sheffield Hallam University, Sheffield, UK, 16-19 July 2008 http://shura.shu.ac.uk/549/1/fulltext.pdf.

Hudson, S., \& Gilbert, D. (2000). Tourism constraints: The neglected dimension in consumer behaviour research. Journal of Travel \& Tourism Marketing, 8 (4), 69-78.

Kamen, J. M. (1970). Quick clustering. Journal of Marketing Research, 7 (2), 199-204.

Lazarsfeld, P.F. (1937). Some remarks on the typological procedures in social research. Zeitschrift fur Socialforschung, 6, 119-139.

Leibenstein, H. (1950), Bandwagon, snob, and Veblen effects in the theory of consumers' demand. The Quarterly Journal of Economics, 64 (2), 183-207.

Lusch, R. F. and Vargo, S. L. (Eds.) (2006a) The Service-Dominant Logic of Marketing: Dialog, Debate, and Directions. Armonk, NY: ME Sharpe. 
Lusch, R.F., \& Vargo, S.L. (2006b). Service-dominant logic as a foundation for a general theory. In R.F. Lusch and S.L. Vargo (Eds.) The Service-Dominant Logic of Marketing: Dialog, Debate, and Directions, 406-20. Armonk, NY: ME. Sharpe.

Mathwick, C., Malhotra, N., \& Rigdon, E. (2001). Experiential value: conceptualization, measurement and application in the catalog and Internet shopping environment. Journal of Retailing, 77 (1), 39-56.

Matthews, I., (2013). Marketing Trends presentations 2013 review. http://www.incosmetics.com/en/Online-Press-Centre/Normal--Industryarticles/marketingtrends2013review/.

McClelland, D.C. (1998). Identifying competencies with behavioral-event interviews. Psychological Science, 9, 331-3339.

Milgrom, P., \& Roberts, J. (1986). Price and advertising signals of product quality. Journal of Political Economy, 94, (4), 796-821.

Mitchell, V. W. (2001). Re-conceptualizing consumer store image processing using perceived risk. Journal of Business Research, 54 (2), 167-172.

Otnes, C.C., Ilhan, B.C., \& Kulkarni, A. (2012). The language of marketplace rituals: Implications for customer experience management. Journal of Retailing 88 (3), 367-383.

Popper, K. (1961). The Logic of Scientific Discovery. New York, NY: Science.

Ragin, C. (2000). Fuzzy set social science. Chicago, IL: Chicago University Press.

Ragin, C. (2008). Redesigning Social Inquiry. Chicago, IL: University of Chicago Press. 
Roberts, S., \& Pashler, H. (2000). How persuasive is a good fit? A comment on theory testing. Psychological Review. 107, 358-367.

Sharma, U. \& Black, P. (2001). Look good, feel better: Beauty therapy as emotional labour. Sociology, 35(4): 913-31.

Sharma, A., \& Stafford, T. F. (2000). The effect of retail atmospherics on customers' perceptions of salespeople and customer persuasion: An empirical investigation. Journal of Business Research, 49 (2), 183-191.

Simon, H.A. (2009). Science seeks parsimony, not simplicity searching for pattern in phenomena. In Zellner, A., Keuzenkamp, H.A., \& McAleer, M. (2009). Simplicity, inference and modelling: Keeping it sophisticatedly simple (pp. 32-72). Cambridge, UK: Cambridge University Press, working paper available at http://digitalcollections.library.cmu.edu/awweb/awarchive?type=file \&item=47027.

Sirgy, M.J., Grewal, D., \& Mangleburg, T. (2000). Retail environment, self-congruity, and retail patronage: An integrative model and a research agenda, Journal of Business Research, 49, 127-138.

Tatzel, M. (2002). "Money worlds' and well-being: An integration of money dispositions, materialism and price-related behavior. Journal of Economic Psychology, 23, 103-126.

Toerien, M., \& Kitzinger, C. (2007). Emotional labour in action: Navigating multiple involvements in the beauty salon. Sociology, 41(4): 645-662.

Urry, J. (2005). The complexity turn. Theory, Culture \& Society, 22, 1-14. 
Üstüner, T. \& Thompson, C. J. (2012). How marketplace performances produce interdependent status games and contested forms of symbolic capital. Journal of Consumer Research, 38, (5) 796-814.

Vargo, S. L., \& Lusch, Robert F. (2004a) 'Evolving to a New Dominant Logic for Marketing’, Journal of Marketing 68(1): 1-17.

Vargo, S. L., \& Lusch, R. F. (2004b). The four services marketing myths: Remnants from a manufacturing model. Journal of Service Research 6(4), 324-35.

Vargo, S. L., \& Lusch, R. F. (2006). Service-dominant logic: What it is, what it is not, what it might be. In R.F. Lusch and S.L. Vargo (Eds.), The Service-Dominant Logic of Marketing: Dialog, Debate, and Directions, 43-56. Armonk, NY: ME Sharpe.

Vargo, S. L. \& Morgan, F. W. (2005). An historical reexamination of the nature of exchange: The service-dominant perspective. Journal of Macromarketing 25(1), 42-53.

Wakefield, K., \& Blodgett, J.G. (1996). The effect of the servicescape on customers' behavioral intentions in leisure service settings. Journal of Services Marketing, 10 (6), 45 - 61.

Woodside, A.G. (2013a). Moving beyond multiple regression analysis to algorithms: Calling for a paradigm shift from symmetric to asymmetric thinking in data analysis, and crafting theory. Journal of Business Research, 66, 463-472.

Woodside, A. G. (2013b). Proposing a new logic for data analysis in marketing and consumer behavior: case study research of large-N survey data for estimating algorithms that accurately profile X (extremely high-use) consumers. Journal of Global Scholars of Marketing Science, 22 (4), 277-289. 
Woodside, A. G., Frey, L.L., \& Daily, R.T. (1989). Linking service quality, customer satisfaction and behavioral intention: From general to applied frameworks of the service encounter. Journal of Health Care Marketing, 9 (4), 5-17.

Woodside, A.G., \& Sims, J. T., (1976). Retail sales transactions and customer "purchase pal” effects on buying behavior. Journal of Retailing, 52 (3), 57-64, 95.

Woodside, A.G., \& Zhang, M. (2012). Identifying X-consumers using causal recipes: 'whales' and 'jumbo shrimps' casino gamblers,” Journal of Gambling Studies, 28, 13-26.

Zeithaml, V.A., Berry, L.L., \& Parasuraman, A. (1996). The behavioral consequences of service quality. Journal of Marketing, 60 (2), 31-46. 
Appendix Table 1

Beauty Salon/Spa Facets:

(1) Architecture; (2) People_Quality; (3) Aroma, Temp, Lighting; (4) Music; (5) Displays; (6) Personnel_Numb

1. Architecture (touch)

Aroma, temp, light

4. Music

5. Product displays

6. People number sufficient

\begin{tabular}{|c|c|c|c|c|c|c|}
\hline & \multicolumn{6}{|c|}{ Component } \\
\hline & 1 & 2 & 3 & 4 & 5 & 6 \\
\hline Architecture & .850 & & & & & \\
\hline Wallpaper & .764 & & & & & \\
\hline Decoration & .748 & & & & & \\
\hline $\begin{array}{l}\text { Professionalism of } \\
\text { personnel }\end{array}$ & & .790 & & & & \\
\hline Friendliness of personnel & & .778 & & & & \\
\hline Crowdedness level & & .673 & & & & \\
\hline Professional uniform & & .641 & & & & \\
\hline Aroma & & & .835 & & & \\
\hline Temperature level & & & .691 & & & \\
\hline Luminance level & & & .587 & & & \\
\hline Background Music & & & & .830 & & \\
\hline Music Volume & & & & .801 & & \\
\hline Efficient layout & & & & & .746 & \\
\hline Item display & & & & & .663 & \\
\hline $\begin{array}{l}\text { Sufficient number of } \\
\text { personnel }\end{array}$ & & & & & & .839 \\
\hline Rotated Sums of Squared & & & & & & \\
\hline Loadings & 2.71 & 2.61 & 1.89 & 1.88 & 1.53 & 0.99 \\
\hline$\%$ variance & 18.04 & 17.42 & 12.61 & 12.52 & 10.19 & 6.60 \\
\hline
\end{tabular}

Note. Table 1 includes only factor loadings having values above 0.50 . 


\section{Appendix Table 2}

Service Outcomes:

(1) Responsiveness; (2) Price_Acceptance; (3) Spatial; (4) Treatment; (5) Arousal_Pleasure; (6) Service_Quality

1. Responsiveness

\begin{tabular}{|c|c|c|c|c|c|c|}
\hline & \multicolumn{6}{|c|}{ Component } \\
\hline & 1 & 2 & 3 & 4 & 5 & 6 \\
\hline Responsiveness & .870 & & & & & \\
\hline Politeness & .757 & & & & & \\
\hline Initiative & .755 & & & & & \\
\hline $\begin{array}{l}\text { Acceptable price range for } \\
\text { the consumption level of } \\
\text { local community }\end{array}$ & & .861 & & & & \\
\hline $\begin{array}{l}\text { Acceptable price range for } \\
\text { me }\end{array}$ & & .812 & & & & \\
\hline Good value for money & & .749 & & & & \\
\hline Spatial surrounding & & & .820 & & & \\
\hline Good ambience & & & .751 & & & \\
\hline Nice style & & & .729 & & & \\
\hline Effective health treatment & & & & .855 & & \\
\hline Effective facial treatment & & & & .691 & & \\
\hline Effective body treatment & & & & .655 & & \\
\hline Arouse pleasure & & & & & .773 & \\
\hline High aesthetics value & & & & & .753 & \\
\hline $\begin{array}{l}\text { The experience is worth } \\
\text { the price }\end{array}$ & & & & & & .778 \\
\hline Superior service quality & & & & & & .723 \\
\hline $\begin{array}{l}\text { Rotation Sums of } \\
\text { Squared Loadings }\end{array}$ & 2.49 & 2.45 & 2.22 & 2.07 & 1.72 & 1.60 \\
\hline$\%$ of Variance & 15.54 & 15.34 & 13.90 & 12.91 & 10.72 & 9.99 \\
\hline
\end{tabular}

Note. Table 2 includes only factor loadings having values above 0.50 . 

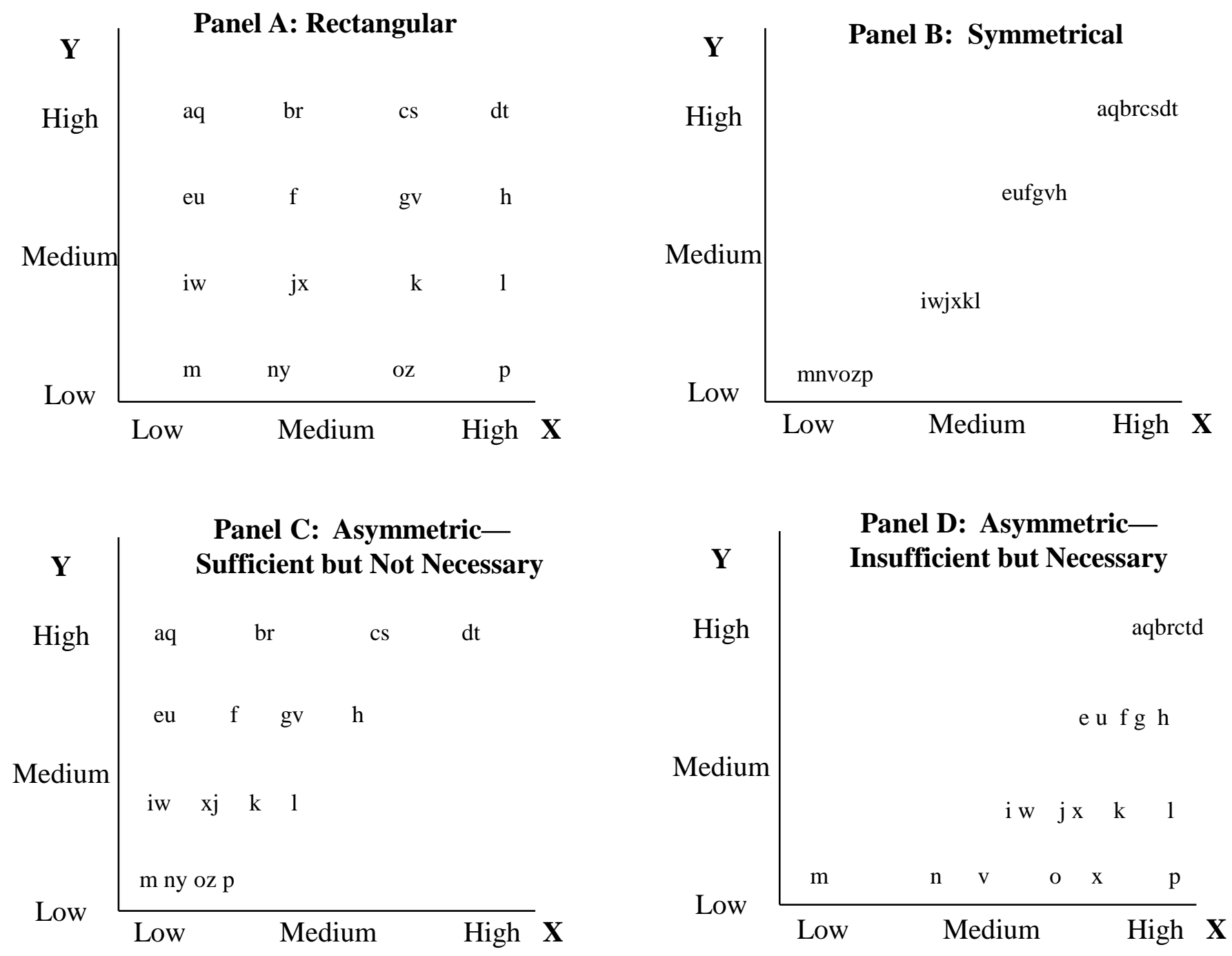

\section{Figure 1}

Hypothetical Relationships where $X$ is a Complex Configural Condition (e.g., $C \cdot T \cdot H \cdot Z$ ) and $Y$ is a Service Outcome Condition (e.g., Customer Intention-to-Return) 


\section{Figure 2: Foundational Complex Configural Model}

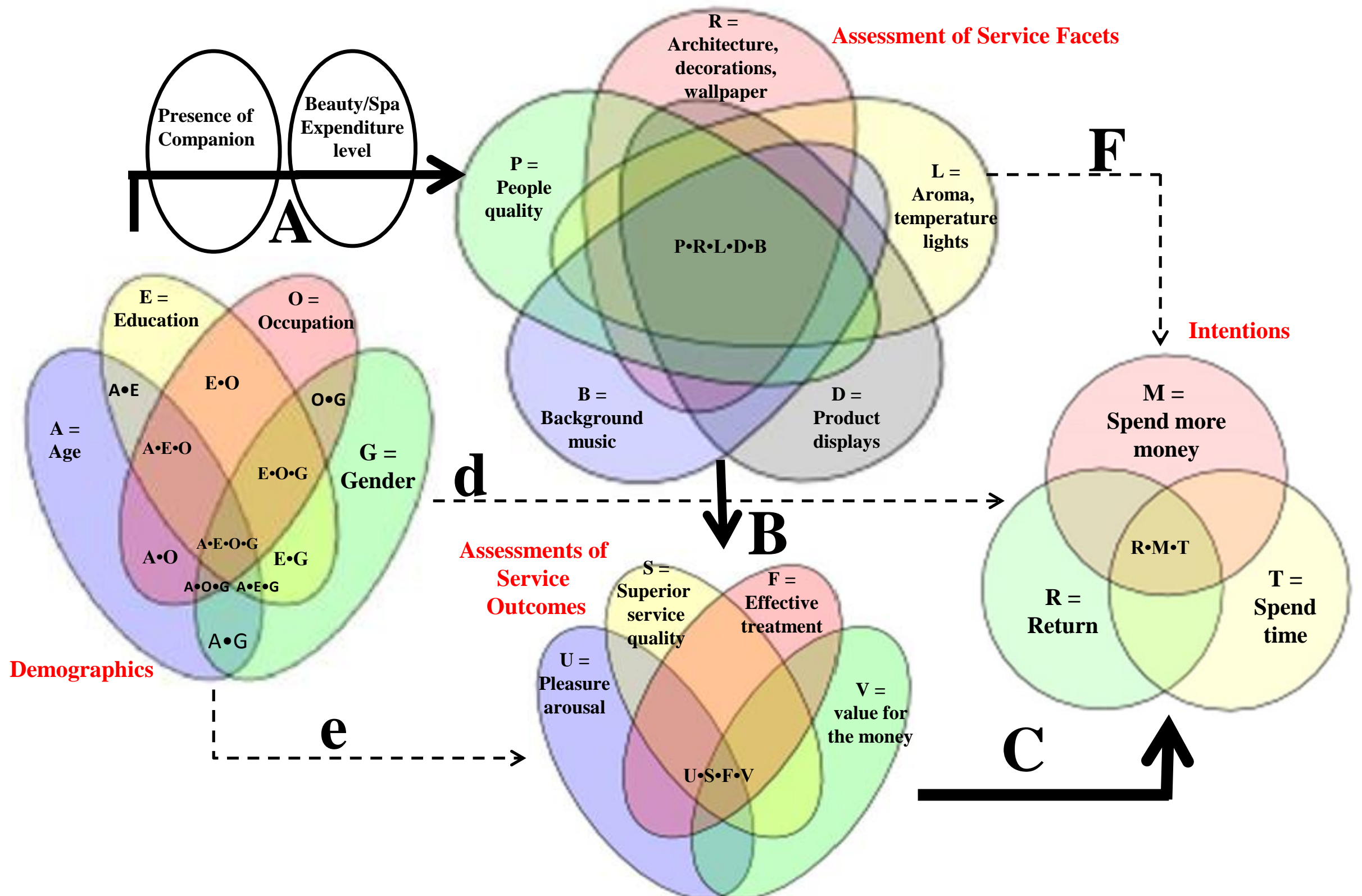

Note. Thick arrows indicate propositions regarding effective algorithms; thin and dotted arrows indicate predictions of low accuracy. 
Figure 3

Sufficient Number of Professional Service Providers: Indicates a Necessary but Insufficient Condition (Numbers indicate number of cases (customers).)

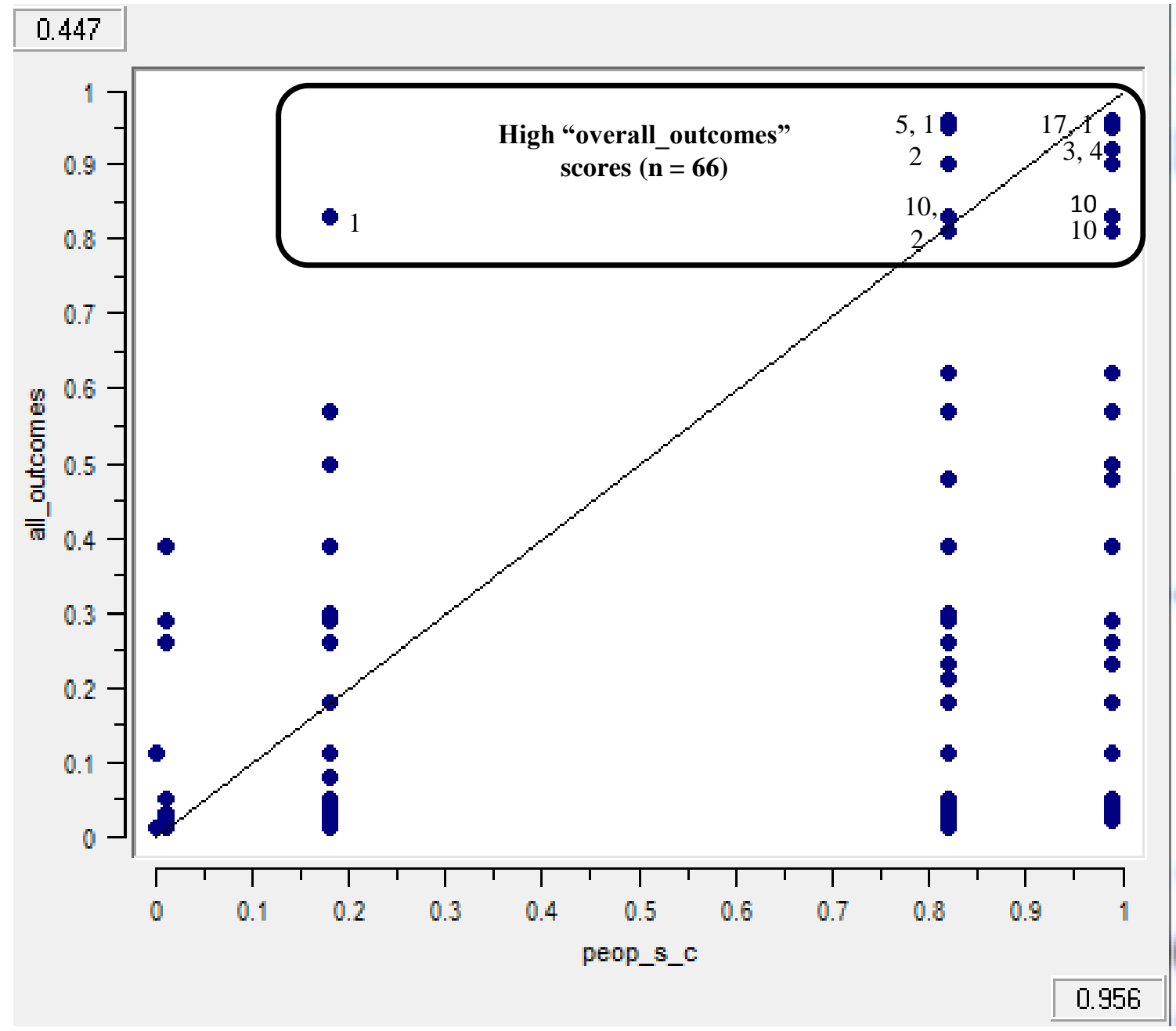

Note. 65 of 66 cases high "all_outcome" scores have high scores in evaluating the beauty salon/spa but The majority of cases with high scores in beauty/salon/spa have low "all_outcome" scores. 


\section{Figure 4}

\section{Specific Findings for Key Configural Models}

Models predicting high scores in people quality:

$\sim$ companion $\sim$ servicew $\bullet$ housekeeper $\bullet$ female $\sim$ edu $\sim$ age

$\sim$ spa_expend $\bullet \sim$ companion $\bullet \sim$ servicew $\bullet \sim$ housekeeper $\sim$ female $\bullet \sim$ edu $\bullet$ age

spa_expend•companion•servicew $\bullet$ housekeeper•female•edu•age
$\mathbf{R}=$

\section{Assessment of Service Facets}

Architecture

decorations,

wallpaper

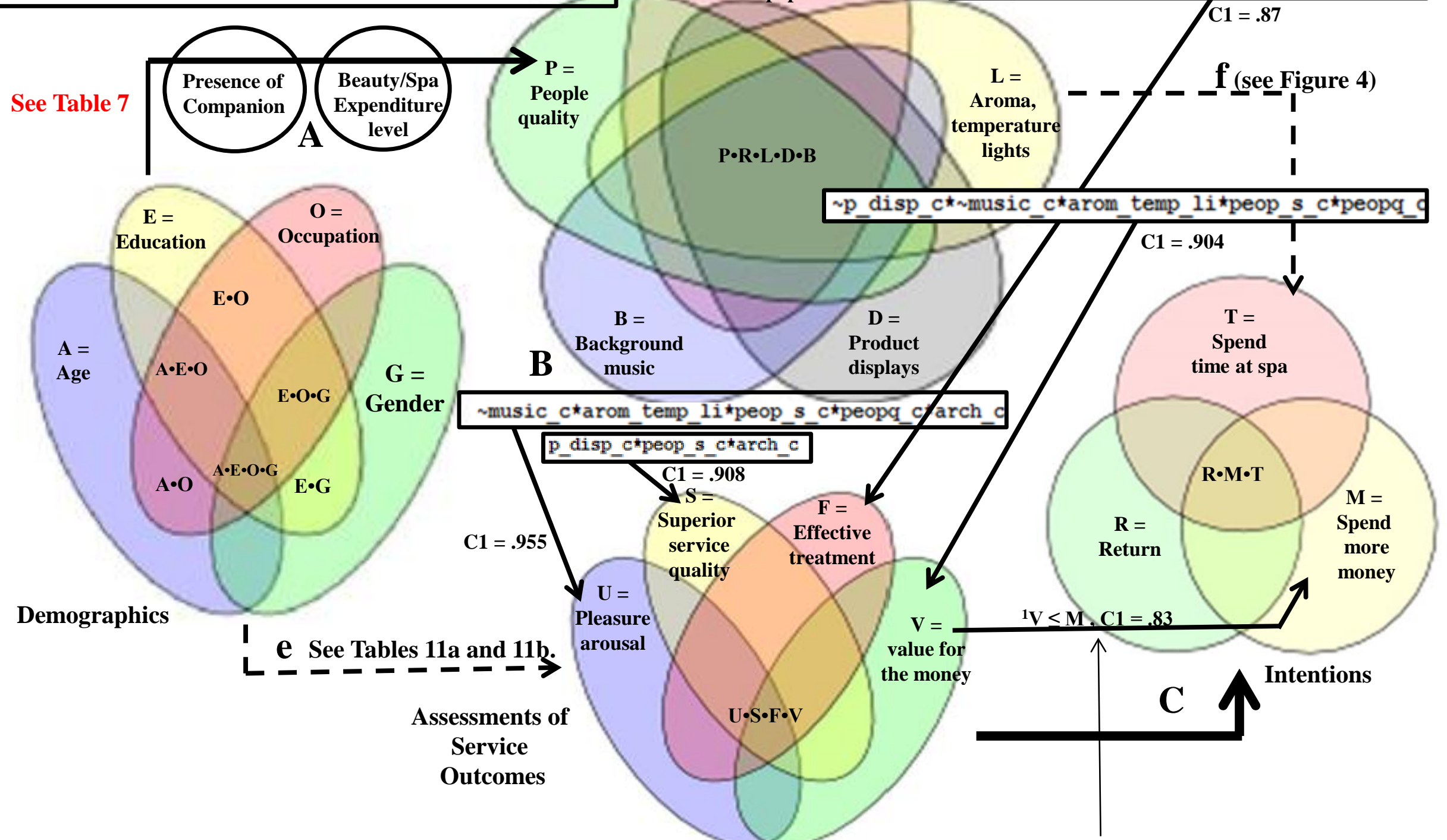

Note. ${ }^{1}$ For example, high scores for value-for-the-money predict high scores for spend more money with consistency (C1) equal to .83 . 
Figure 5

Algorithm for décor, sufficient people, product display predicting return intention

(Décor • Sufficient_People • Product_Displays $\leq$ Return)

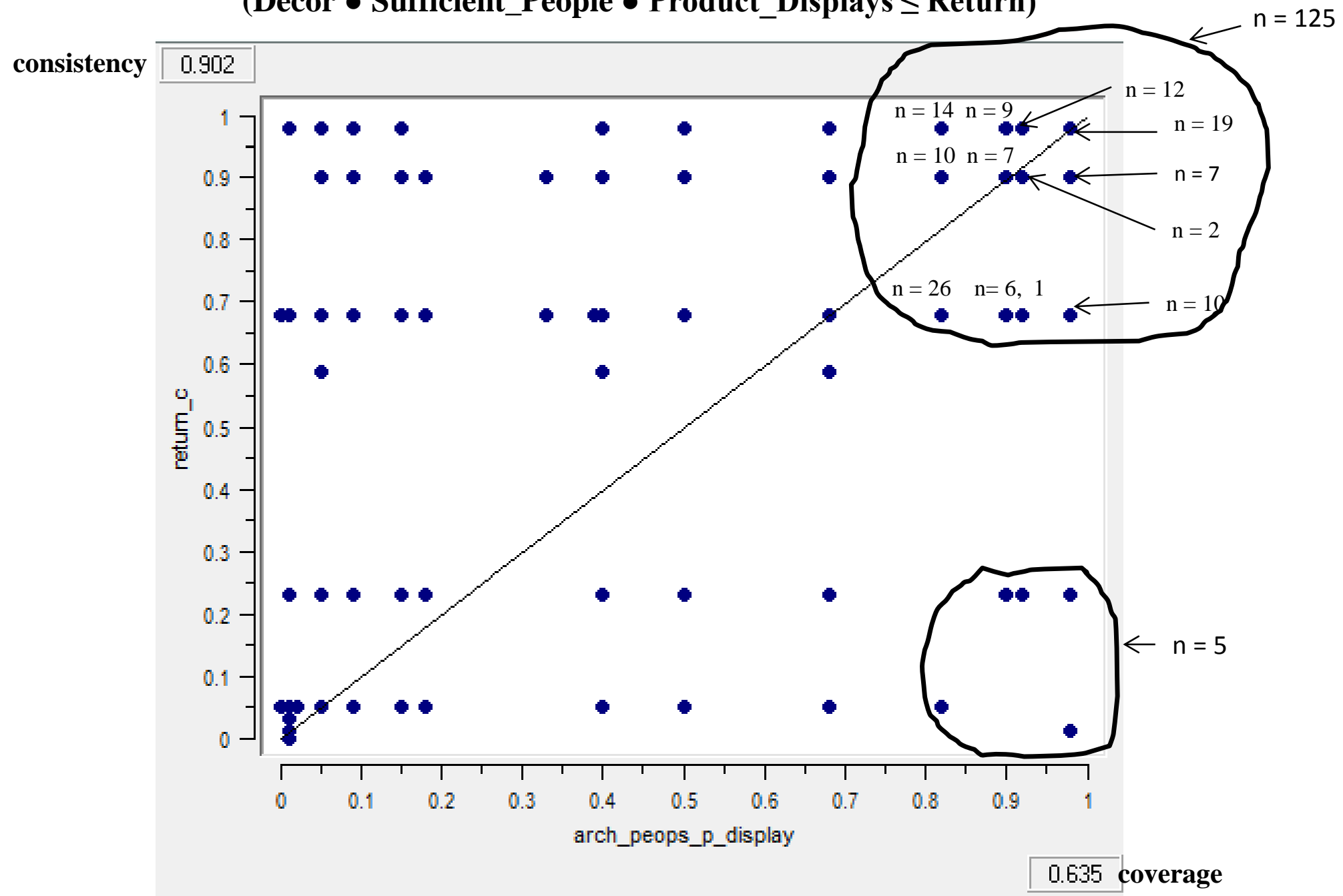

Note. 125 customers with high score for this algorithm have high return intention membership scores above 0.65 and only 5 customers with high scores for this algorithm have member ship scores below 0.65 ; thus, five times more customers with high scores on the algorithm have high versus low return intentions. 
Table 1

Correlations of Demographics with Service Facet Evaluations

\begin{tabular}{|c|c|c|c|c|c|c|c|c|c|c|c|c|}
\hline & & \multirow{2}{*}{\multicolumn{5}{|c|}{ Demographics }} & & & & & & \\
\hline & & & & & & & & & rvice Face & & & \\
\hline & & Age & $\underset{e}{\text { female_v_mal }}$ & Education & housekeeper & serviceworker & $\begin{array}{c}\text { arch_dec_wal } \\
\text { l }\end{array}$ & $\underset{y}{\text { people_qualit }}$ & $\begin{array}{l}\text { aroma_temp_ } \\
\text { lights }\end{array}$ & music & displays & $\begin{array}{l}\text { Sufficient } \\
\text { number of } \\
\text { personnel }\end{array}$ \\
\hline \multirow[t]{3}{*}{ Age } & Pearson Correlation & 1 & .007 & $-.201^{\mathrm{xn}}$ & $.219^{\mathrm{kx}}$ & $-.296^{\mathrm{kx}}$ & .090 & .016 & .012 & -.001 & .070 & .017 \\
\hline & Sig. (2-tailed) & & .892 & .000 & .000 & .000 & .062 & .733 & .806 & .985 & .144 & .730 \\
\hline & $\mathrm{N}$ & 436 & 436 & 436 & 436 & 436 & 436 & 436 & 436 & 436 & 436 & 436 \\
\hline \multirow[t]{3}{*}{ female_v_male } & Pearson Correlation & .007 & 1 & .054 & .059 & $.104^{*}$ & .081 & .091 & .074 & $.096^{*}$ & $.116^{*}$ & .011 \\
\hline & Sig. (2-tailed) & .892 & & .256 & .220 & .030 & .090 & .058 & .123 & .046 & .015 & .820 \\
\hline & $\mathrm{N}$ & 436 & 436 & 436 & 436 & 436 & 436 & 436 & 436 & 436 & 436 & 436 \\
\hline \multirow[t]{3}{*}{ Education } & Pearson Correlation & $-.201^{\star \pi}$ & .054 & 1 & $-.227^{\star \pi}$ & .039 & .022 & $.137^{\kappa \pi}$ & .025 & -.016 & .033 & .016 \\
\hline & Sig. (2-tailed) & .000 & .256 & & .000 & .411 & .654 & .004 & .602 & .737 & .485 & .739 \\
\hline & $\mathrm{N}$ & 436 & 436 & 436 & 436 & 436 & 436 & 436 & 436 & 436 & 436 & 436 \\
\hline \multirow[t]{3}{*}{ housekeeper } & Pearson Correlation & $.219^{n \pi}$ & .059 & $-.227^{* \pi}$ & 1 & $-.263^{\text {*x }}$ & .042 & .024 & -.019 & .030 & .040 & .028 \\
\hline & Sig. (2-tailed) & .000 & .220 & .000 & & .000 & .381 & .617 & .700 & .534 & .410 & .560 \\
\hline & $N$ & 436 & 436 & 436 & 436 & 436 & 436 & 436 & 436 & 436 & 436 & 436 \\
\hline \multirow[t]{3}{*}{ serviceworker } & Pearson Correlation & $-.296^{\kappa \pi}$ & $.104^{\pi}$ & .039 & $-.263^{n \pi}$ & 1 & -.057 & .038 & .019 & .024 & -.069 & -.020 \\
\hline & Sig. (2-tailed) & .000 & .030 & .411 & .000 & & .239 & .426 & .698 & .616 & .151 & .677 \\
\hline & $\mathrm{N}$ & -126 & 126 & -126 & 126 & 426 & -426 & -426 & 126 & -426 & -426 & -426 \\
\hline \multirow[t]{3}{*}{ arch_dec_wall } & Pearson Correlation & .090 & .081 & .022 & .042 & -.057 & 1 & $.524^{\mathrm{nx}}$ & $.478^{\mathrm{xx}}$ & $.402^{n x}$ & $.651^{\mathrm{Nx}}$ & $.481^{\pi n}$ \\
\hline & Sig. (2-tailed) & .062 & .090 & .654 & .381 & .239 & & .000 & .000 & .000 & .000 & .000 \\
\hline & $\mathrm{N}$ & 436 & 436 & 436 & 436 & 436 & 436 & 436 & 436 & 436 & 436 & 436 \\
\hline \multirow[t]{3}{*}{ people_quality } & Pearson Correlation & .016 & .091 & $.137^{\kappa \pi}$ & .024 & .038 & $.524^{\pi \pi}$ & 1 & $.544^{\pi \pi}$ & $.454^{\pi \pi}$ & $.520^{k \pi}$ & $.556^{n \pi}$ \\
\hline & Sig. (2-tailed) & .733 & .058 & .004 & .617 & .426 & .000 & & .000 & .000 & .000 & .000 \\
\hline & $N$ & 436 & 436 & 436 & 436 & 436 & 436 & 436 & 436 & 436 & 436 & 436 \\
\hline \multirow[t]{3}{*}{ aroma_temp_lights } & Pearson Correlation & .012 & .074 & .025 & -.019 & .019 & $.478^{\text {nx }}$ & $.544^{\mathrm{xN}}$ & 1 & $.598^{\mathrm{Nx}}$ & $.467^{n x}$ & $.375^{\mathrm{kx}}$ \\
\hline & Sig. (2-tailed) & .806 & .123 & .602 & .700 & .698 & .000 & .000 & & .000 & .000 & .000 \\
\hline & $\mathrm{N}$ & 436 & 436 & 436 & 436 & 436 & 436 & 436 & 436 & 436 & 436 & 436 \\
\hline \multirow[t]{3}{*}{ music } & Pearson Correlation & -.001 & $.096^{x}$ & -.016 & .030 & .024 & $.402^{\mathrm{nx}}$ & $.454^{\times x}$ & $.598^{\mathrm{n}}$ & 1 & $.385^{\kappa x}$ & $.413^{\mathrm{nx}}$ \\
\hline & Sig. (2-tailed) & .985 & .046 & .737 & .534 & .616 & .000 & .000 & .000 & & .000 & .000 \\
\hline & $N$ & 436 & 436 & 436 & 436 & 436 & 436 & 436 & 436 & 436 & 436 & 436 \\
\hline \multirow[t]{3}{*}{ displays } & Pearson Correlation & .070 & $.116^{x}$ & .033 & .040 & -.069 & $.651^{n \pi}$ & $.520^{\pi \pi}$ & $.467^{\pi \pi}$ & $.385^{* \pi}$ & 1 & $.443^{k \pi}$ \\
\hline & Sig. (2-tailed) & .144 & .015 & .485 & .410 & .151 & .000 & .000 & .000 & .000 & & .000 \\
\hline & $\mathrm{N}$ & 436 & 436 & 436 & 436 & 436 & 436 & 436 & 436 & 436 & 436 & 436 \\
\hline Sufficient number of & Pearson Correlation & .017 & .011 & .016 & .028 & -.020 & $.481^{n \pi}$ & $.556^{\mathrm{Nx}}$ & $.375^{N \pi}$ & $.413^{\text {kn }}$ & $.443^{n \pi}$ & 1 \\
\hline personnel & Sig. (2-tailed) & .730 & .820 & .739 & .560 & .677 & .000 & .000 & .000 & .000 & .000 & \\
\hline & $\mathrm{N}$ & 436 & 436 & 436 & 436 & 436 & 436 & 436 & 436 & 436 & 436 & 436 \\
\hline
\end{tabular}

Note. Correlations indicate few significant symmetric relationships among demographics and service facet evaluations.

Correlations among service facet evaluations are significant and medium in effect size. 
Table 2

Correlations of Demographics with Experience Assessments and Intentions

\begin{tabular}{|c|c|c|c|c|c|c|c|c|c|c|c|}
\hline & & \multicolumn{5}{|c|}{ Demographics } & \multicolumn{5}{|c|}{ Experience Assessments and Intentions } \\
\hline & & Age & $\underset{e}{\text { female_v }} \underset{\text { emal }}{ }$ & Education & housekeeper & serviceworkel & $\begin{array}{l}\text { arousal_plea } \\
\text { sure }\end{array}$ & $\begin{array}{c}\text { effective_treat } \\
\text { ment }\end{array}$ & return & $\begin{array}{c}\text { spendmore_ti } \\
\text { me_money }\end{array}$ & $\begin{array}{c}\text { superior_serv } \\
\text { ice_quality }\end{array}$ \\
\hline \multirow[t]{3}{*}{ Age } & Pearson Correlation & 1 & .007 & $-.201^{\pi n}$ & $.219^{\mathrm{nn}}$ & $-.296^{\text {"N }}$ & -.041 & .038 & -.071 & $-.139^{\text {"m }}$ & .000 \\
\hline & Sig. (2-tailed) & & .892 & .000 & .000 & .000 & .398 & .426 & .138 & .004 & .999 \\
\hline & $\mathrm{N}$ & 436 & 436 & 436 & 436 & 436 & 436 & 436 & 436 & 436 & 436 \\
\hline \multirow[t]{3}{*}{ female_v_male } & Pearson Correlation & .007 & 1 & .054 & .059 & .104 & .088 & .057 & .037 & -.031 & .073 \\
\hline & Sig. (2-tailed) & .892 & & .256 & .220 & .030 & .066 & .238 & .442 & .519 & .126 \\
\hline & $\mathrm{N}$ & 436 & 436 & 436 & 436 & 436 & 436 & 436 & 436 & 436 & 436 \\
\hline \multirow[t]{3}{*}{ Education } & Pearson Correlation & $-.201^{\pi x}$ & .054 & 1 & $-.227^{\star x}$ & .039 & $.101^{x}$ & .026 & .062 & .011 & .091 \\
\hline & Sig. (2-tailed) & .000 & .256 & & .000 & .411 & .035 & .594 & .197 & .812 & .056 \\
\hline & $\mathrm{N}$ & 436 & 436 & 436 & 436 & 436 & 436 & 436 & 436 & 436 & 436 \\
\hline \multirow[t]{3}{*}{ housekeeper } & Pearson Correlation & $.219^{\mathrm{nx}}$ & .059 & $-.227^{\mathrm{x}}$ & 1 & $-.263^{\mathrm{kn}}$ & .039 & .077 & .045 & .037 & .016 \\
\hline & Sig. (2-tailed) & .000 & .220 & .000 & & .000 & .416 & .110 & .352 & .439 & .731 \\
\hline & $\mathrm{N}$ & 436 & 436 & 436 & 436 & 436 & 436 & 436 & 436 & 436 & 436 \\
\hline \multirow[t]{3}{*}{ serviceworker } & Pearson Correlation & $-.296^{2 \pi}$ & $.104^{x}$ & .039 & $-.263^{\mathrm{ma}}$ & & $.102^{x}$ & .044 & .084 & .024 & .016 \\
\hline & Sig. (2-tailed) & .000 & .030 & .411 & .000 & & .033 & .360 & .079 & .621 & .732 \\
\hline & $\mathrm{N}$ & .326 & 136 & 136 & -136 & 136 & 436 & 436 & 436 & 436 & 436 \\
\hline \multirow[t]{3}{*}{ arousal_pleasure } & Pearson Correlation & -.041 & .088 & $.101^{n}$ & .039 & $.102^{x}$ & 1 & $.483^{\prime \prime \prime}$ & $.480^{m \prime \prime}$ & $.407^{n n}$ & $.609^{111}$ \\
\hline & Sig. (2-tailed) & .398 & .066 & .035 & .416 & .033 & & .000 & .000 & .000 & .000 \\
\hline & $\mathrm{N}$ & 436 & 436 & 436 & 436 & 436 & 436 & 436 & 436 & 436 & 436 \\
\hline \multirow[t]{3}{*}{ effective_treatment } & Pearson Correlation & .038 & .057 & .026 & .077 & .044 & $.483^{\mathrm{nx}}$ & 1 & $.390^{\mathrm{xt}}$ & $.319^{x x}$ & $.527^{\mathrm{nt}}$ \\
\hline & Sig. (2-tailed) & .426 & .238 & .594 & .110 & .360 & .000 & & .000 & .000 & .000 \\
\hline & $\mathrm{N}$ & 436 & 436 & 436 & 436 & 436 & 436 & 436 & 436 & 436 & 436 \\
\hline \multirow[t]{3}{*}{ return } & Pearson Correlation & -.071 & .037 & .062 & .045 & .084 & $.480^{n \pi}$ & $.390^{\mathrm{nn}}$ & 1 & $.647^{\mathrm{xn}}$ & $.520^{\mathrm{xN}}$ \\
\hline & Sig. (2-tailed) & .138 & .442 & .197 & .352 & .079 & .000 & .000 & & .000 & .000 \\
\hline & $\mathrm{N}$ & 436 & 436 & 436 & 436 & 436 & 436 & 436 & 436 & 436 & 436 \\
\hline \multirow[t]{3}{*}{ spendmore_time_money } & Pearson Correlation & $-.139^{\mathrm{nn}}$ & -.031 & .011 & .037 & .024 & $.407^{\mathrm{nn}}$ & $.319^{\mathrm{mn}}$ & $1^{.647^{\mathrm{kn}}}$ & 1 & $.439^{\text {nt }}$ \\
\hline & Sig. (2-tailed) & .004 & .519 & .812 & .439 & .621 & .000 & .000 & .000 & & .000 \\
\hline & $\mathrm{N}$ & 436 & 436 & 436 & 436 & 436 & 436 & 436 & 436 & 436 & 436 \\
\hline \multirow[t]{3}{*}{ superior_service_quality } & Pearson Correlation & .000 & .073 & .091 & .016 & .016 & $.609^{n x}$ & $.527^{\mathrm{nk}}$ & $.520^{\mathrm{n}}$ & $.439^{212}$ & 1 \\
\hline & Sig. (2-tailed) & .999 & .126 & .056 & .731 & .732 & .000 & .000 & .000 & .000 & \\
\hline & N & 436 & 436 & 436 & 436 & 436 & 436 & 436 & 436 & 436 & 436 \\
\hline
\end{tabular}

Note. Correlations includes few significant symmetric relationships among demographics and experience assessments and Intentions. Correlations among outcomes, experience assessments, and intentions are positive and highly significant. 
Table 3

Correlations of Beauty Salon/Spa Facets and Intentions

\begin{tabular}{|c|c|c|c|c|c|c|c|c|c|}
\hline & & & & Ambience & & & & Inte & itions \\
\hline & & $\begin{array}{c}\text { arch_dec_wal } \\
\text { I }\end{array}$ & people_qual & $\begin{array}{c}\text { aroma_temp_ } \\
\text { see }\end{array}$ & music & display & $\begin{array}{l}\text { Sufficient } \\
\text { number of } \\
\text { personnel }\end{array}$ & return & $\begin{array}{l}\text { spendmore_ti } \\
\text { me_money }\end{array}$ \\
\hline arch_dec_wall & Pearson Correlation & 1 & $.524^{\mathrm{kn}}$ & $.478^{\text {xx }}$ & $.402^{\mathrm{kn}}$ & $.651^{\wedge x}$ & $.481^{\times 1}$ & $.455^{\mathrm{kn}}$ & $.357^{\pi \times}$ \\
\hline & Sig. (2-tailed) & & .000 & .000 & .000 & .000 & .000 & .000 & .000 \\
\hline & $\mathrm{N}$ & 436 & 436 & 436 & 436 & 436 & 436 & 436 & 436 \\
\hline people_qual & Pearson Correlation & $.524^{\pi x}$ & 1 & $.544^{\pi \pi}$ & $.454^{\pi \pi}$ & $.520^{\pi \pi}$ & $.556^{\wedge 1}$ & $.420^{\pi x}$ & $.386^{\pi n}$ \\
\hline & Sig. (2-tailed) & .000 & & .000 & .000 & .000 & .000 & .000 & .000 \\
\hline & $\mathrm{N}$ & 436 & 436 & 436 & 436 & 436 & 436 & 436 & 436 \\
\hline aroma_temp_see & Pearson Correlation & $.478^{\mathrm{xx}}$ & $.544^{\mathrm{xx}}$ & 1 & $.598^{\pi x}$ & $.467^{\times x}$ & $.375^{\mathrm{x}}$ & $.339^{\mathrm{kx}}$ & $.316^{\mathrm{kn}}$ \\
\hline & Sig. (2-tailed) & .000 & .000 & & .000 & .000 & .000 & .000 & .000 \\
\hline & $\mathrm{N}$ & 436 & 436 & 436 & 436 & 436 & 436 & 436 & 436 \\
\hline music & Pearson Correlation & $.402^{n x}$ & $.454^{\times x}$ & $.598^{\mathrm{kx}}$ & 1 & $.385^{k \pi}$ & $.413^{\mathrm{n}}$ & $.320^{\mathrm{Nx}}$ & $.253^{\mathrm{kn}}$ \\
\hline & Sig. (2-tailed) & .000 & .000 & .000 & & .000 & .000 & .000 & .000 \\
\hline & $\mathrm{N}$ & 436 & 436 & 436 & 436 & 436 & 436 & 436 & 436 \\
\hline display & Pearson Correlation & $.651^{\star \pi}$ & $.520^{\pi \pi}$ & $.467^{\pi \pi}$ & $.385^{\pi \pi}$ & 1 & $.443^{\text {Nx }}$ & $.381^{\pi \pi}$ & $.333^{k \pi}$ \\
\hline & Sig. (2-tailed) & .000 & .000 & .000 & .000 & & .000 & .000 & .000 \\
\hline & $N$ & 436 & 436 & 436 & 436 & 436 & 436 & 436 & 436 \\
\hline Sufficient number of & Pearson Correlation & $.481^{\pi x}$ & $.556^{\pi \pi}$ & $.375^{x \pi}$ & $.413^{\pi x}$ & $.443^{n \pi}$ & 1 & $.368^{x \pi}$ & $.325^{\pi x}$ \\
\hline personnel & Sig. (2-tailed) & .000 & .000 & .000 & .000 & .000 & & .000 & .000 \\
\hline & $N$ & 436 & 436 & 436 & 436 & 436 & 436 & 436 & 436 \\
\hline return & Pearson Correlation & $.455^{\mathrm{n}}$ & $.420^{\pi \pi}$ & $.339^{\star \pi}$ & $.320^{\pi \pi}$ & $.381^{\pi \pi}$ & $.368^{n x}$ & 1 & $.647^{\pi \times}$ \\
\hline & Sig. (2-tailed) & .000 & .000 & .000 & .000 & .000 & .000 & & .000 \\
\hline & $N$ & 436 & 436 & 436 & 436 & 436 & 436 & 436 & 436 \\
\hline spendmore_time_money & Pearson Correlation & $.357^{\mathrm{xx}}$ & $.386^{n \pi}$ & $.316^{\pi \pi}$ & $.253^{\pi \pi}$ & $.333^{\pi x}$ & $.325^{\text {NI }}$ & $.647^{\pi \pi}$ & 1 \\
\hline & Sig. (2-tailed) & .000 & .000 & .000 & .000 & .000 & .000 & .000 & \\
\hline & $N$ & 436 & 436 & 436 & 436 & 436 & 436 & 436 & 436 \\
\hline
\end{tabular}




\section{Table 4}

\section{Correlations of All Dimensions of Customers' Evaluations and Intentions}

\begin{tabular}{|c|c|c|c|c|c|c|c|c|c|c|c|c|}
\hline & touch & people_qualit & $\begin{array}{c}\text { aroma_temp_ } \\
\text { lights }\end{array}$ & music & displays & $\begin{array}{l}\text { Sufficient } \\
\text { number of } \\
\text { personnel }\end{array}$ & $\begin{array}{c}\text { valueformone } \\
y\end{array}$ & $\begin{array}{c}\text { superior_serv } \\
\text { ice_quality }\end{array}$ & $\begin{array}{l}\text { arousal_plea } \\
\text { sure }\end{array}$ & $\begin{array}{l}\text { effective_treat } \\
\text { ment }\end{array}$ & return & $\begin{array}{l}\text { spendmore_ti } \\
\text { me_money }\end{array}$ \\
\hline touch & 1.000 & .524 & .478 & .402 & .651 & .481 & .458 & .486 & .447 & .374 & .455 & .357 \\
\hline people_quality & .524 & 1.000 & .544 & .454 & .520 & .556 & .402 & .458 & .459 & .425 & .420 & .386 \\
\hline aroma_temp_lights & .478 & .544 & 1.000 & .598 & .467 & .375 & .347 & .391 & .454 & .333 & .339 & .316 \\
\hline music & .402 & .454 & .598 & 1.000 & .385 & .413 & .299 & .374 & .341 & .279 & .320 & .253 \\
\hline displays & .651 & .520 & .467 & .385 & 1.000 & .443 & .398 & .458 & .452 & .409 & .381 & .333 \\
\hline $\begin{array}{l}\text { Sufficient number of } \\
\text { personnel }\end{array}$ & .481 & .556 & .375 & .413 & .443 & 1.000 & .405 & .406 & .355 & .329 & .368 & .325 \\
\hline valueformoney & .458 & .402 & .347 & .299 & .398 & .405 & 1.000 & .523 & .460 & .453 & .548 & .562 \\
\hline superior_service_quality & .486 & .458 & .391 & .374 & .458 & .406 & .523 & 1.000 & .609 & .527 & .520 & .439 \\
\hline arousal_pleasure & .447 & .459 & .454 & .341 & .452 & .355 & .460 & .609 & 1.000 & .483 & .480 & .407 \\
\hline effective_treatment & .374 & .425 & .333 & .279 & .409 & .329 & .453 & .527 & .483 & 1.000 & .390 & .319 \\
\hline return & .455 & .420 & .339 & .320 & .381 & .368 & .548 & .520 & .480 & .390 & 1.000 & .647 \\
\hline spendmore_time_money & .357 & .386 & .316 & .253 & .333 & .325 & .562 & .439 & .407 & .319 & .647 & 1.000 \\
\hline
\end{tabular}

\section{Quick Cluster Summary}

touch $\stackrel{.65}{\longleftrightarrow}$ displays

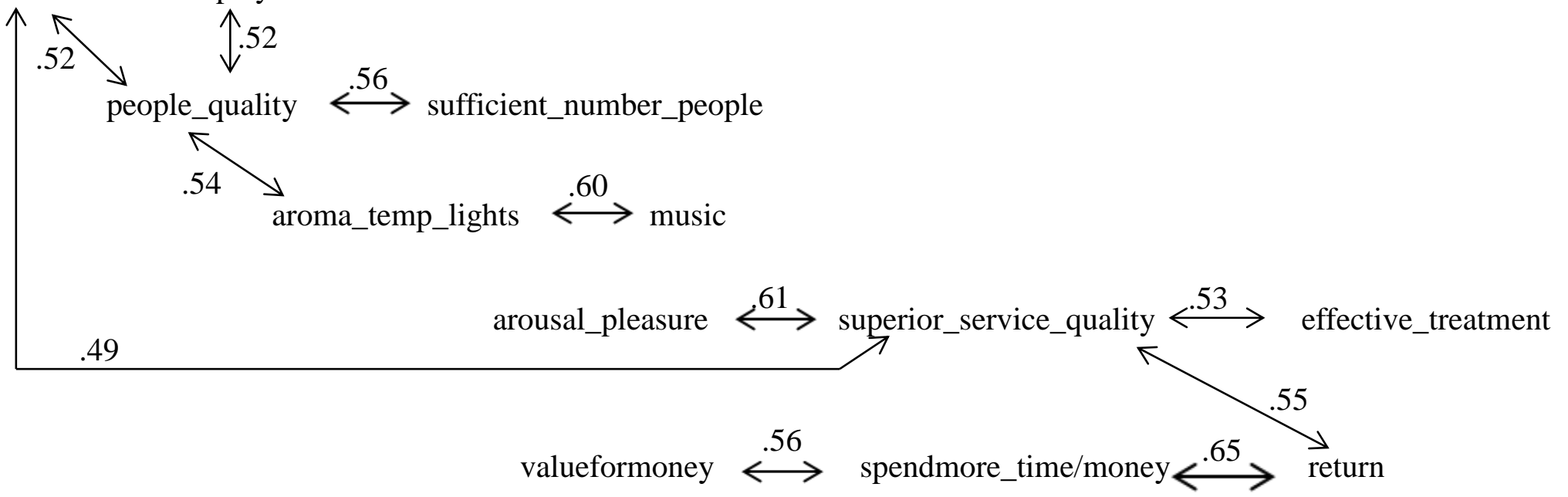


Table 5

Two Outcomes: Effective Treatment and Service Quality Segments

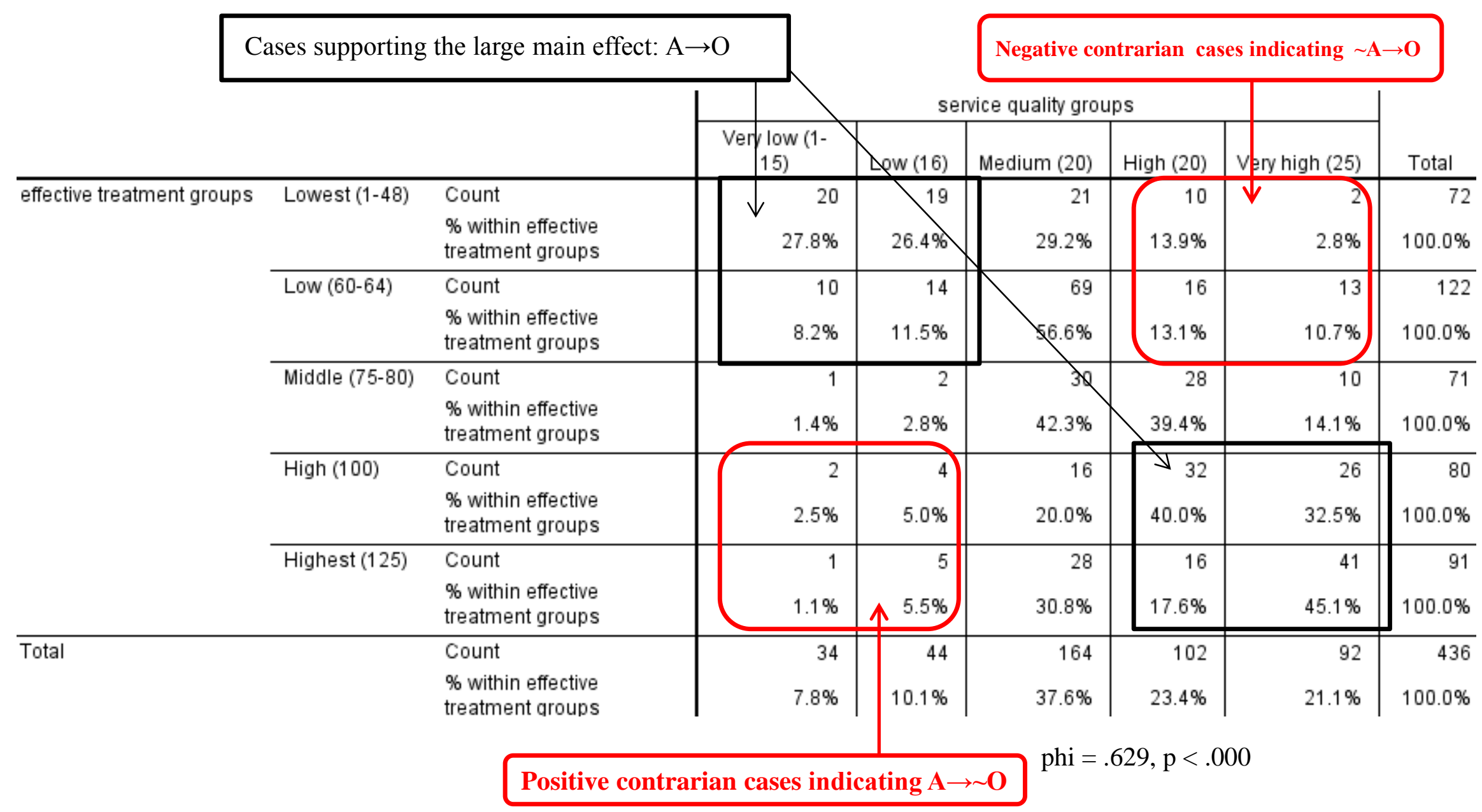

Key. $\mathrm{A}=$ antecedent condition (e.g., effective treatment); $\mathrm{O}=$ outcome condition (e.g., service quality).

Note. The significant main effect relationship indicates a large effect size (Cohen, 1977), phi $^{2}=.40$.

However, negative and positive contrarian cases still occur; the positivistic model does not account for such contrarian cases. 
Table 6

\section{Service Quality and Return Intention Segments}

\begin{tabular}{|c|c|c|c|c|c|c|c|c|}
\hline & & & & & \multicolumn{4}{|c|}{ Negative contrarian cases indicating $\sim \mathbf{A} \rightarrow \mathbf{O}$} \\
\hline & & & \multicolumn{5}{|c|}{ return_5groups } & \multirow[b]{2}{*}{ Total } \\
\hline & & & $4-9$ & $12-15$ & 16 & 20 & 25 & \\
\hline \multirow[t]{10}{*}{ service quality groups } & Very low (1-15) & Count & 17 & 4 & 9 & 3 & & 34 \\
\hline & & $\begin{array}{l}\% \text { within service quality } \\
\text { groups }\end{array}$ & $50.0 \%$ & $11.8 \%$ & $26.5 \%$ & $8.8 \%$ & $2.9 \%$ & $100.0 \%$ \\
\hline & Low (16) & Count & 10 & 18 & 10 & 4 & 2 & 44 \\
\hline & & $\begin{array}{l}\% \text { within service quality } \\
\text { groups }\end{array}$ & $22.7 \%$ & $40.9 \%$ & $22.7 \%$ & $9.1 \%$ & $4.5 \%$ & $100.0 \%$ \\
\hline & Medium (20) & Count & 5 & 14 & 101 & 24 & 20 & 164 \\
\hline & & $\begin{array}{l}\% \text { within service quality } \\
\text { groups }\end{array}$ & $3.0 \%$ & $8.5 \%$ & $61.6 \%$ & $14.6 \%$ & $12.2 \%$ & $100.0 \%$ \\
\hline & High (20) & Count & 2 & 5 & 43 & 31 & 21 & 102 \\
\hline & & $\begin{array}{l}\% \text { within service quality } \\
\text { groups }\end{array}$ & $2.0 \%$ & $4.9 \%$ & $42.2 \%$ & $30.4 \%$ & $20.6 \%$ & $100.0 \%$ \\
\hline & Very high (25) & Count & 2 & 2 & 26 & 18 & 44 & 92 \\
\hline & & $\begin{array}{l}\% \text { within service quality } \\
\text { groups }\end{array}$ & $\uparrow 2.2 \%$ & $2.2 \%$ & $28.3 \%$ & $19.6 \%$ & $47.8 \%$ & $100.0 \%$ \\
\hline \multirow[t]{3}{*}{ Total } & & Count & 36 & 43 & 189 & 80 & 88 & 436 \\
\hline & & $\begin{array}{l}\% \text { within service quality } \\
\text { groups }\end{array}$ & $8.3 \%$ & $9.9 \%$ & $43.3 \%$ & $18.3 \%$ & $20.2 \%$ & $100.0 \%$ \\
\hline & & \multicolumn{3}{|c|}{ Positive contrarian cases indicating $\mathrm{A} \rightarrow \sim 0$} & \multicolumn{3}{|c|}{ phi $=.736, \mathrm{p}<.000$} & \\
\hline
\end{tabular}

Key: $\sim \mathrm{A} \rightarrow \mathrm{O}=$ low score for the antecedent condition leads to high score for the outcome condition $\mathrm{A} \rightarrow \sim \mathrm{O}=$ high score for the antecedent condition leads to low score in the outcome condition

Note. The two sets of contrarian cases are counter to the main large effect size $\left(\mathrm{phi}^{2}=.54\right)$ positive relationship, $\mathrm{A} \rightarrow \mathrm{O}$, 
Table 7

Demographic, Companion, and Beauty Saloon/Spa Expenditure

Algorithm Models Predicting High People Q (Service Professional Evaluations)

\section{Model ${ }^{1}$}

$1 \sim$ compan $\star \sim$ servicew $w^{\star}$ housek female $^{\star} \sim$ educ_c $c^{\star} \sim$ age_c

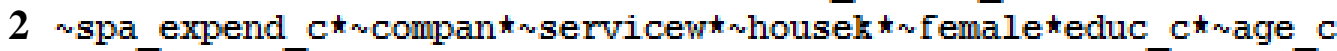

3 spa_expend_ $\bar{c}^{\star \sim} \sim$ compan ${ }^{\star}$ servicew $w^{\star} \sim$ housek ${ }^{\star} \sim$ female $e^{\star} \sim$ educ $\bar{c}^{\star} \sim$ age $\bar{c}$

4 spa_expend_c ${ }^{\star}$ compan ${ }^{\star}$ servicew ${ }^{\star} \sim$ housek ${ }^{\star}$ female ${ }^{\star}$ educ_c ${ }^{\star}$ age_c solution coverage: 0.069127

solution consistency: 0.935638

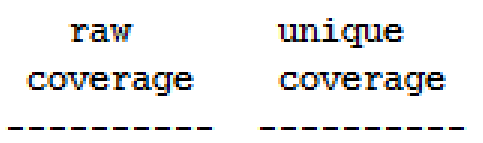

0.025859

0.005423

0.004401

0.033443

\subsection{9}

0.005423

0.004401

0.033443 consistency

0.941345

0.938776

0.957265

0.928026

Notes. ${ }^{1}$ For example, model 1 states a case (customer) with a high score for no companion, not a service worker, a housekeeper, female, with low education and young will give a high score in service professional evaluations.

2 Note that the presence of companion contributes positively and negatively to the outcome (high score in people_q) depending on the additional antecedents in each of these four complex antecedent conditions-it is not so much a question of whether or not companion influences the outcome but under what circumstances (contingencies) companion does so.

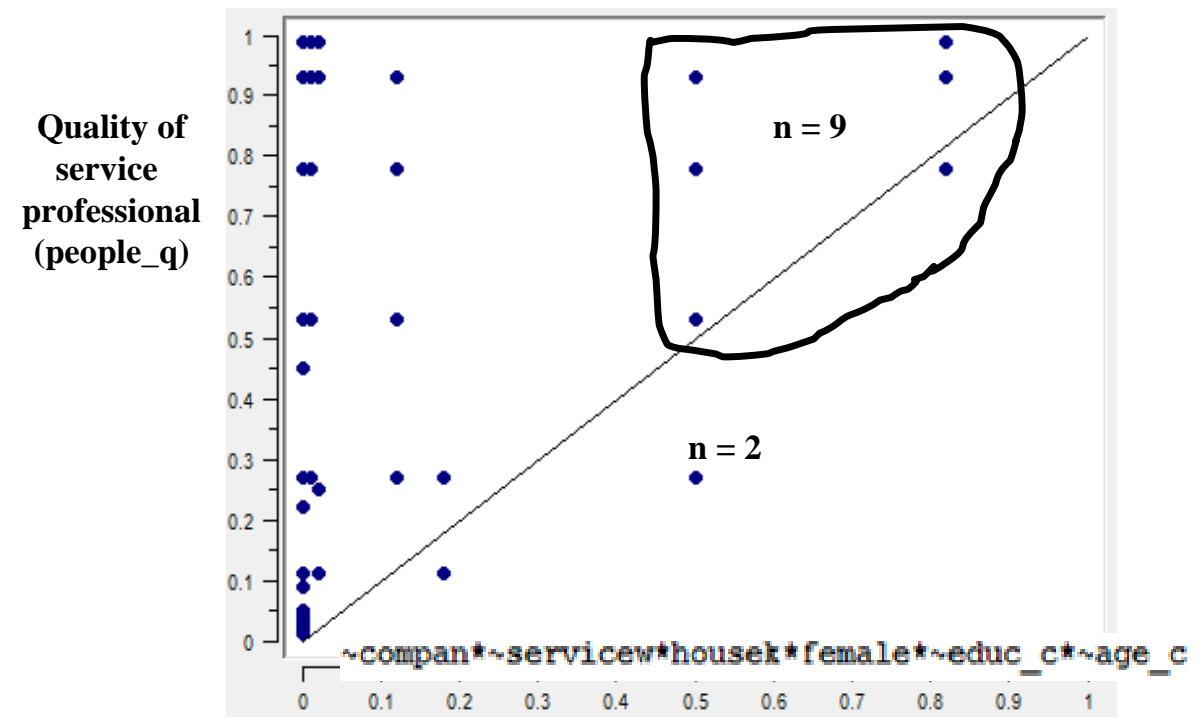

Figure 3 XY Plot of Model 1 


\section{Models Predicting High Global Outcomes}

a. Model (only one) for high score for overall service facets

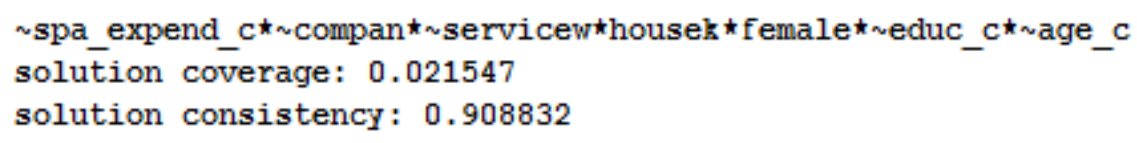

$\begin{array}{ccl}\begin{array}{c}\text { raw } \\ \text { coverage }\end{array} & \begin{array}{l}\text { unique } \\ \text { coverage }\end{array} & \text { consistency } \\ --0---- & ------ & ----- \\ 0.021547 & 0.021547 & 0.908832\end{array}$

Note. Explanation: customers with high scores in the configuration of low expenditure per spa visit, visiting without a companion, a housekeeper, not a service worker, and is a female, with low education and are young give high evaluations overall to service facets.

\section{Models for high scores for not overall service facets}

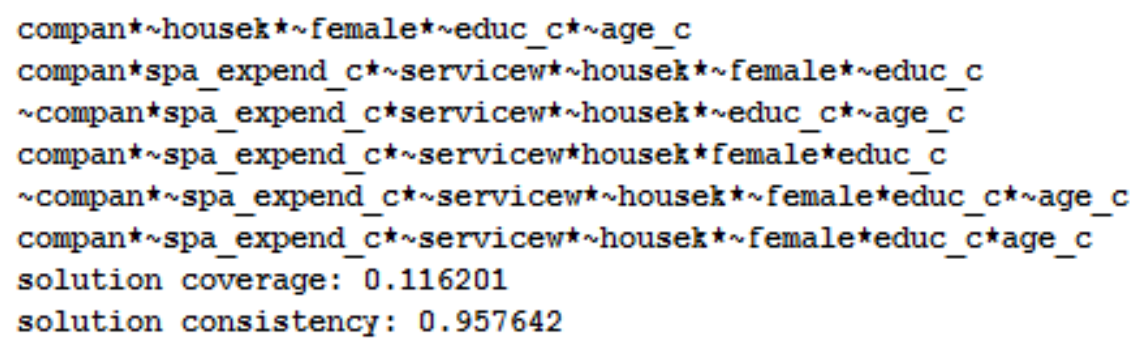

\section{b. Service facet models for high scores for overall service outcomes}

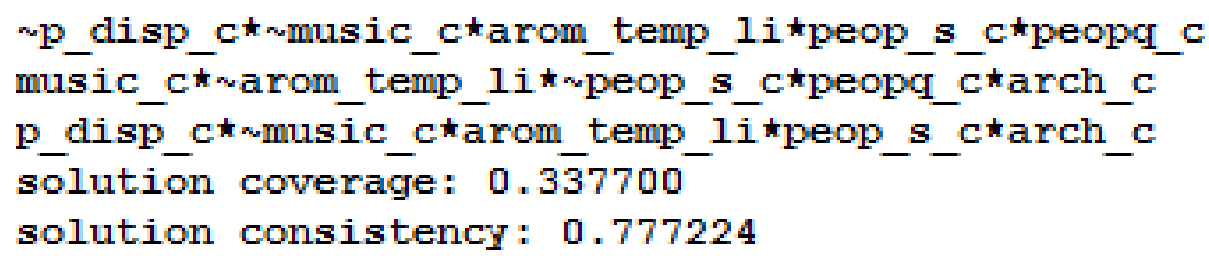

$\begin{array}{cll}\begin{array}{c}\text { raw } \\ \text { coverage }\end{array} & \begin{array}{l}\text { unique } \\ \text { coverage }\end{array} & \text { consistency } \\ ------ & ------- & ------- \\ 0.023858 & 0.015350 & 0.977240 \\ 0.019135 & 0.010696 & 0.941880 \\ 0.051537 & 0.051537 & 0.938053 \\ 0.015037 & 0.015037 & 0.981859 \\ 0.005105 & 0.004862 & 1.000000 \\ 0.012745 & 0.009932 & 0.978667\end{array}$

Note. Positive people evaluations (for quality or sufficient number of people) appear in all three models for high evaluations for overall service outcomes (i.e., the configuration pleasure arousal, effective spa treatment, overall service quality, and value for the money.

\begin{tabular}{|c|c|c|c|}
\hline c. Models of service outcomes predicting overall intentions & $\begin{array}{l}\text { raw } \\
\text { coverage }\end{array}$ & $\begin{array}{l}\text { unique } \\
\text { coverage }\end{array}$ & consistency \\
\hline p_arousal_c`value_m_c & 0.696970 & 0.113648 & 0.821986 \\
\hline $\begin{array}{l}\text { value_m_c }{ }^{\star} \text { eff_treat_c } \\
\text { solution coverage: } \overline{0} .7591 \\
\text { solution consistency: } 0.8\end{array}$ & $\begin{array}{l}0.645502 \\
50 \\
11979\end{array}$ & 0.062181 & 0.846482 \\
\hline
\end{tabular}


Table 9a

Outcome Models with Demographics and Service Outcome Evaluations Predicting High Return Intentions

$\sim$ servicew $\sim$ housek ${ }^{\star}$ duc_c ${ }^{\star} \sim$ age_ckeff_treat_ckserqual_c

$\sim$ servicew $\sim$ housek ${ }^{\star}$ female ${ }^{\star}$ educ_c $c^{\star}$ spa_expend_c $c^{\star}$ eff_treat_c $c^{\star} \sim p$ arousal_c

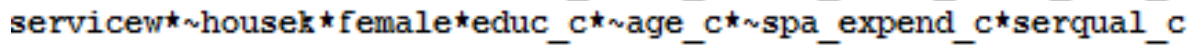

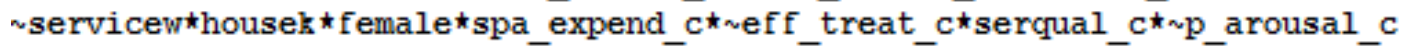

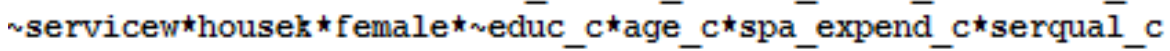

service $w^{\star} \sim$ housek ${ }^{\star}$ female ${ }^{\star}$ educ_ $\bar{c}^{\star} \sim$ age $c^{\star}$ serqual_c $c^{\star} \bar{p}$ arousal_ $\bar{c}$

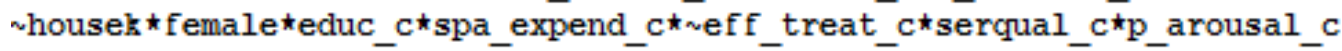

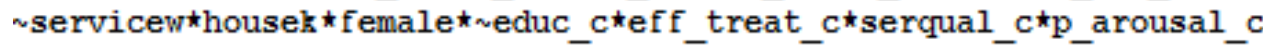

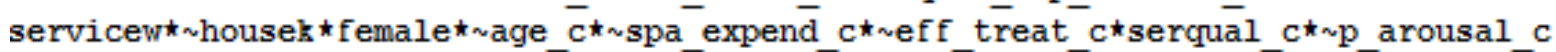

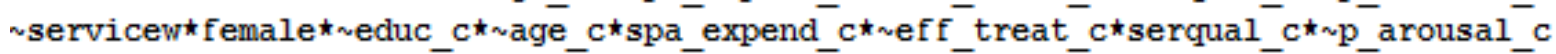

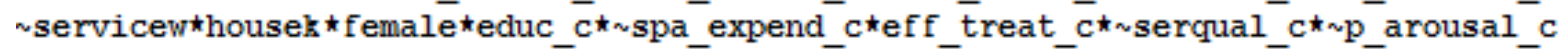

$\sim$ servicew ${ }^{\star} \sim$ housek female $^{\star}$ educ_c $\mathrm{c}^{\star} \sim$ age _c $\mathrm{c}^{\star}$ spa

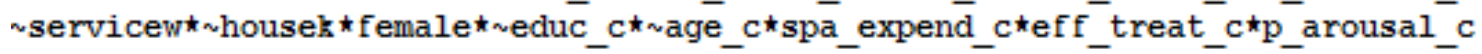

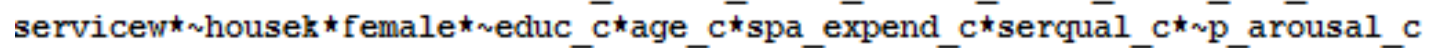

servicew $\sim$ housek ${ }^{\star}$ female ${ }^{\star} \sim$ educ_c ${ }^{\star}$ age_c $c^{\star}$ eff_treat_c ${ }^{\star}$ serqual_c ${ }^{\star} \sim p$ arousal_c

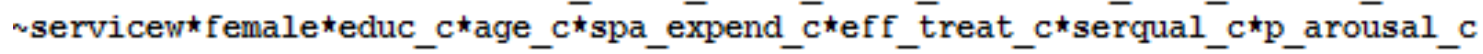

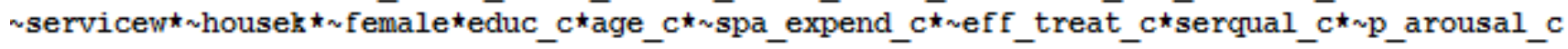

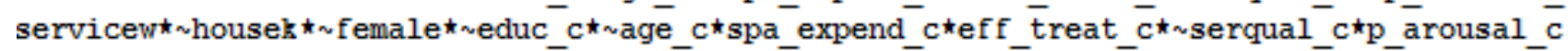

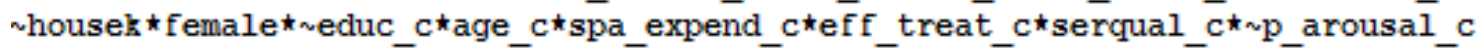

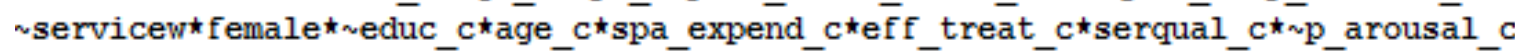

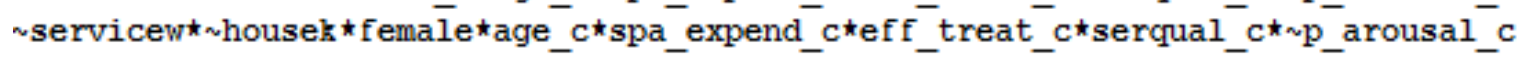

solution coverage: 0.588023

solution consistency: 0.951616

\begin{tabular}{|c|c|c|}
\hline $\begin{array}{c}\text { raw } \\
\text { coverage }\end{array}$ & $\begin{array}{l}\text { unique } \\
\text { coverage }\end{array}$ & consistency \\
\hline ---------- & ---------- & ---------- \\
\hline 0.174005 & 0.067611 & 0.967676 \\
\hline 0.094602 & 0.005378 & 0.949062 \\
\hline 0.082276 & 0.005211 & 0.970832 \\
\hline 0.024853 & 0.002405 & 0.982827 \\
\hline 0.057322 & 0.005211 & 0.972238 \\
\hline 0.139197 & 0.035376 & 0.945112 \\
\hline 0.204771 & 0.026757 & 0.954829 \\
\hline 0.058258 & 0.012861 & 0.961942 \\
\hline 0.032469 & 0.005746 & 0.987805 \\
\hline 0.042457 & 0.002572 & 0.973946 \\
\hline 0.009587 & 0.003975 & 0.993079 \\
\hline 0.095137 & 0.003775 & 0.974008 \\
\hline 0.052412 & 0.012026 & 0.981238 \\
\hline 0.026757 & 0.004576 & 0.968561 \\
\hline 0.027759 & 0.003407 & 0.965157 \\
\hline 0.160877 & 0.030131 & 0.961469 \\
\hline 0.006681 & 0.002439 & 1.000000 \\
\hline 0.004075 & 0.004075 & 1.000000 \\
\hline 0.065874 & -0.000000 & 0.986987 \\
\hline 0.068413 & -0.000000 & 0.993692 \\
\hline 0.092832 & -0.000000 & 0.961925 \\
\hline
\end{tabular}


Outcome Models with Demographics and Service Outcome Evaluations

Predicting the Negation of Return Intentions

$\sim$ servicew $w^{\star} \sim$ housek ${ }^{\star}$ educ $\mathrm{c}^{\star \sim}$ age $\mathrm{c}^{\star \sim} \sim$ serqual $\mathrm{c}^{\star \sim}$ value $\mathrm{m} \mathrm{c}^{\star} \sim \mathrm{p}$ arousal $\mathrm{c}$

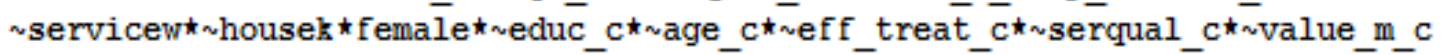

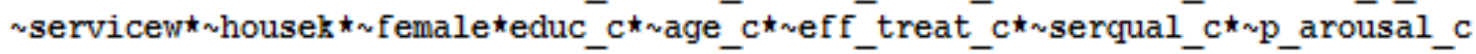

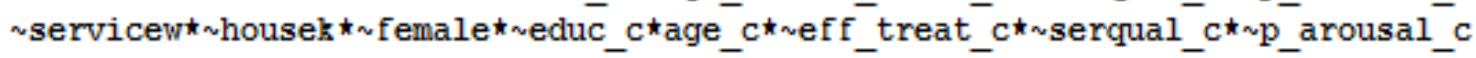

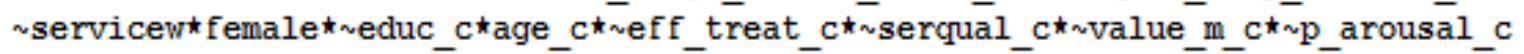

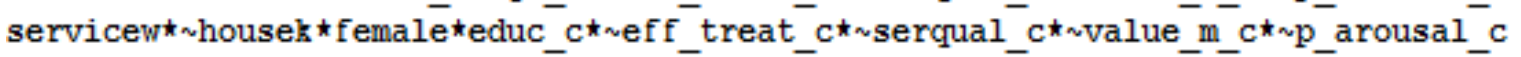

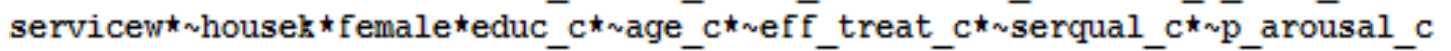
-servicew female ${ }^{\star}$ educ $c^{\star}$ age $c^{\star}$ ef f treat $c^{\star} \sim$ serqual $c^{\star \sim v a l u e ~} \mathrm{~m} \mathrm{c}^{\star} \sim \mathrm{p}$ arousal c

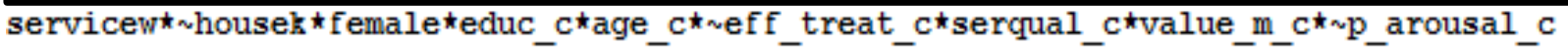

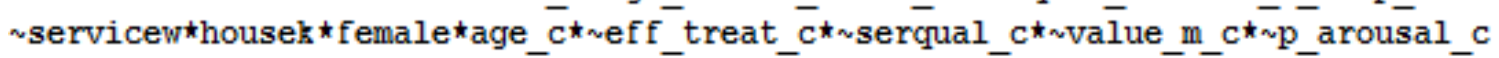

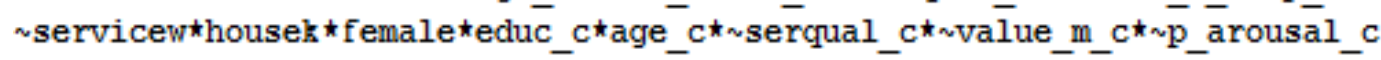
solution coverage: 0.459748 solution consistency: 0.857727

\begin{tabular}{|c|c|c|}
\hline $\begin{array}{c}\text { raw } \\
\text { coverage }\end{array}$ & $\begin{array}{l}\text { unique } \\
\text { coverage }\end{array}$ & consistency \\
\hline---------- & --------- & --------- \\
\hline 0.186842 & 0.060085 & 0.874315 \\
\hline 0.083577 & 0.024810 & 0.873089 \\
\hline 0.036593 & 0.002342 & 0.874126 \\
\hline 0.036958 & 0.027957 & 0.876736 \\
\hline 0.117096 & 0.019760 & 0.883490 \\
\hline 0.100410 & 0.007684 & 0.893229 \\
\hline 0.097629 & 0.004757 & 0.877054 \\
\hline 0.131733 & 0.019906 & 0.871249 \\
\hline 0.051449 & 0.004391 & 0.863636 \\
\hline 0.048302 & 0.000439 & 0.887097 \\
\hline 0.033738 & 0.000000 & 0.874763 \\
\hline
\end{tabular}

\begin{tabular}{|c|c|c|c|}
\hline Table 9c & $\begin{array}{c}\text { raw } \\
\text { coverage }\end{array}$ & $\begin{array}{l}\text { unique } \\
\text { coverage }\end{array}$ & consistency \\
\hline Service Outcomes and Overall Intentions & --------- & --------- & --------- \\
\hline value_m_c* serqual_c & 0.332971 & 0.010501 & 0.779580 \\
\hline value_m_ckserqual_c & 0.493947 & 0.055815 & 0.745373 \\
\hline$\sim$ serqual_ck p p_arousal_c & 0.427943 & 0.001552 & 0.852887 \\
\hline veff_treat_c $\approx \sim$ serqual_c & 0.486188 & 0.001914 & 0.835466 \\
\hline$\sim$ value_m_c ${ }^{\star} \sim$ p_arousal_c & 0.463427 & 0.002793 & 0.819220 \\
\hline $\begin{array}{l}\sim \text { value_m_c }{ }^{\star} \sim \text { eff } f \text { treat_c } \\
\text { solution coverage: } 0 . \overline{7} 64277 \\
\text { solution consistency: } 0.7318\end{array}$ & 0.558244 & 0.008121 & 0.789928 \\
\hline
\end{tabular}


Table 10a

Algorithm Models where High Service Facet Scores Predict High Pleasure Arousal

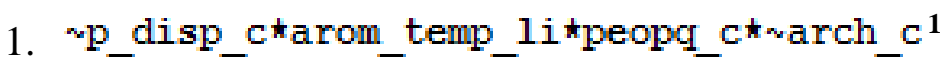

raw
coverage

unique

0.171143

coverage

consistency

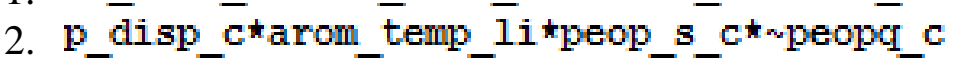

0.226139

0.029206

0.914117

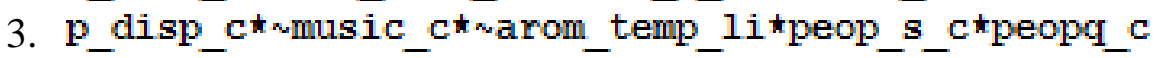

0.130198

0.065384

0.899023

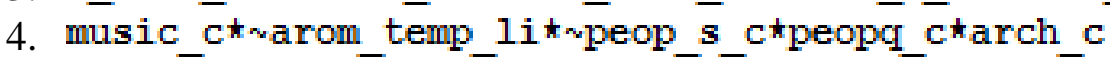

0.079542

0.017502

0.906614

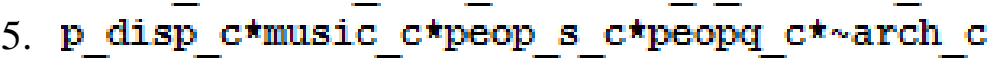

0.235637

0.005727

0.935565

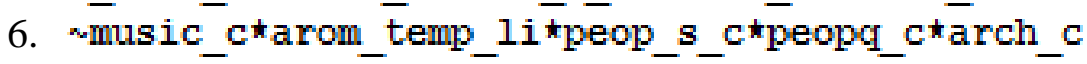
solution coverage: $0.43036 \overline{5}$

0.175519

0.040766

0.937447

solution consistency: 0.877238

Note. 1. For example, model 1 includes negation of product display quality, aroma/temperature/lighting, people (service professional) quality, and not architecture/décor. Note that high scores in people quality appears in five of the six models and one model includes low scores in people quality (contrarian cases).

\section{Table 10b}

\section{Algorithm Models where High Service Facet Scores Predict High Service Quality}

\begin{tabular}{|c|c|c|c|}
\hline & $\begin{array}{c}\text { raw } \\
\text { coverage }\end{array}$ & $\begin{array}{l}\text { unique } \\
\text { coverage }\end{array}$ & consistency \\
\hline & --------- & --------- & -------- \\
\hline p_disp_c^peop_s_ckarch_c & 0.644455 & 0.087184 & 0.907581 \\
\hline p_disp_c*arom_temp_li*peop_s_c ${ }^{\star} \sim$ peopq_c & 0.226182 & 0.009770 & 0.949511 \\
\hline p_disp_ckmusic_ckpeop_s_cћpeopq_c & 0.568186 & 0.016373 & 0.922092 \\
\hline$\sim \bar{p}$ disp_c ${ }^{\star} \sim$ music_c $c^{\star}$ arom_temp_li ${ }^{\star} \sim$ peop_s_c ${ }^{\star} \sim$ arch_c & 0.086040 & 0.015631 & 0.923689 \\
\hline 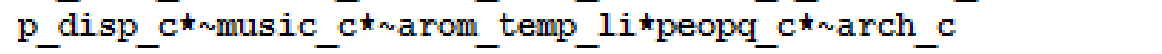 & 0.104737 & 0.002931 & 0.933914 \\
\hline 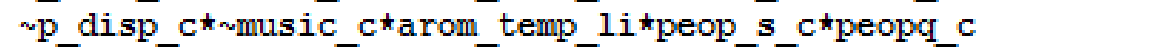 & 0.099347 & 0.000034 & 0.947013 \\
\hline 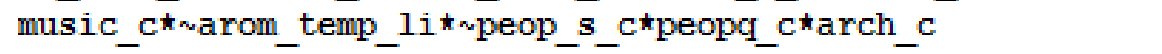 & 0.078763 & 0.006030 & 0.978243 \\
\hline 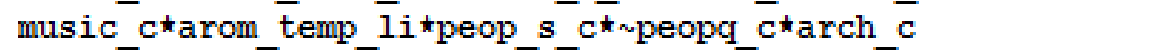 & 0.209406 & 0.007917 & 0.965367 \\
\hline 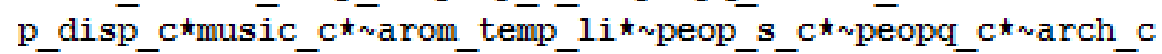 & 0.080346 & 0.010039 & 0.921917 \\
\hline 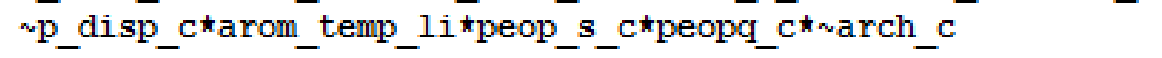 & 0.143108 & 0.000000 & 0.936301 \\
\hline music $c^{\star}$ arom temp $1 \bar{i} \star$ peop_s $c^{\star}$ peopq_c $c^{\star} \sim \operatorname{arch} c^{-}$ & 0.222073 & 0.005592 & 0.938898 \\
\hline
\end{tabular}

solution coverage: 0.774323

solution consistency: 0.881495 
Table 10c

Algorithm Models where High Facet Scores Predict High Value-for-the-Money Outcome

\begin{tabular}{|c|c|c|c|}
\hline & $\begin{array}{c}\text { raw } \\
\text { coverage }\end{array}$ & $\begin{array}{l}\text { unique } \\
\text { coverage }\end{array}$ & consistency \\
\hline & -------- & --------- & --------- \\
\hline 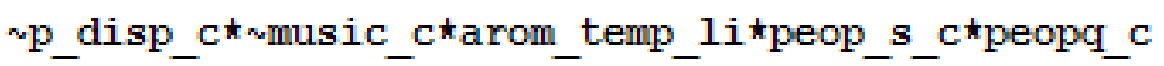 & 0.114723 & 0.015957 & 0.904329 \\
\hline 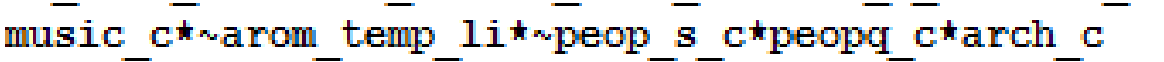 & 0.094154 & 0.023359 & 0.922061 \\
\hline 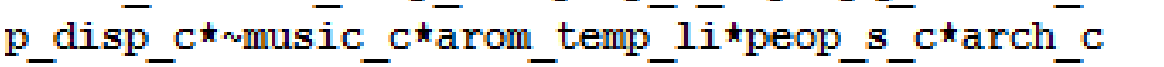 & 0.203382 & 0.013172 & 0.923730 \\
\hline $\begin{array}{l}\text { p_disp_c }{ }^{-} \sim \text { music_c } \\
\text { solution coverage: } 0.275049\end{array}$ & 0.222125 & 0.027139 & 0.908085 \\
\hline
\end{tabular}

Table 10d

Algorithm Models where High Facet Scores Predict High Effective Spa Treatment Outcome

\begin{tabular}{|c|c|c|c|}
\hline & $\begin{array}{c}\text { raw } \\
\text { coverage }\end{array}$ & $\begin{array}{l}\text { unique } \\
\text { coverage }\end{array}$ & consistency \\
\hline $\mathrm{p}$ disp $\mathrm{c}^{\star} \sim$ arom temp li»peop $\mathrm{s} \mathrm{c}^{\star}$ peopg $\mathrm{c}$ & $\begin{array}{l}--------- \\
0.247795\end{array}$ & $\begin{array}{l}--------- \\
0.077464\end{array}$ & $\begin{array}{l}-------- \\
0.871345\end{array}$ \\
\hline 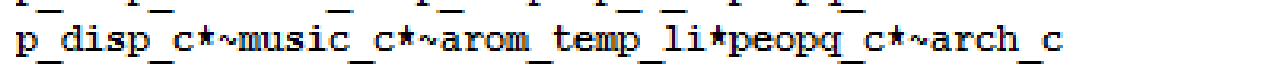 & 0.136703 & 0.002316 & 0.898763 \\
\hline 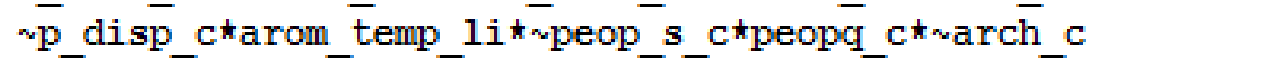 & 0.116840 & 0.021489 & 0.884990 \\
\hline$\sim p_{-}$disp_c ${ }^{\star} \sim$ music_ckärom_temp_li $\bar{i} \star$ peop_s_c ${ }^{\star}$ peopq_c & 0.123831 & 0.003045 & 0.905583 \\
\hline 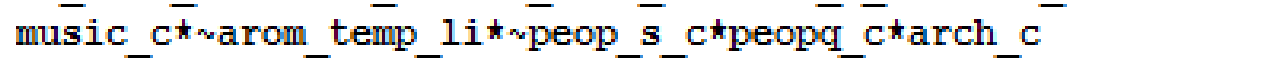 & 0.101660 & 0.006391 & 0.923619 \\
\hline 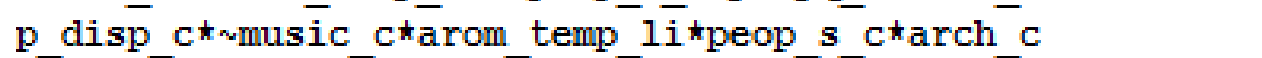 & 0.217380 & 0.066827 & 0.915959 \\
\hline 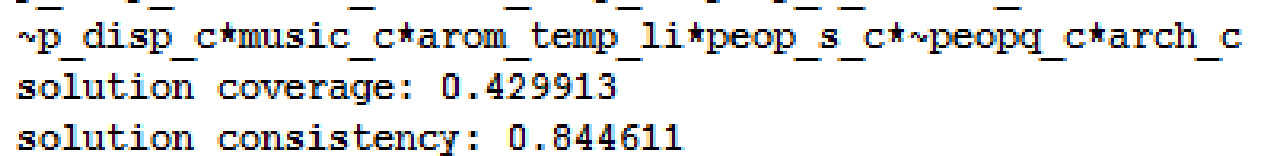 & 0.147851 & 0.028781 & 0.900941 \\
\hline
\end{tabular}


Table 11a

Demographics Indicating High Scores in Service Outcomes

\section{A. Models for Arouse Pleasure}

educ_c ${ }^{\star}$ servicew $\star$ housek $\star \sim$ female educ_ckage_ckservicew ${ }^{\star} \sim$ housek $\sim$ educ_c $c^{\star} \sim$ age $c^{\star} \sim$ servicew ${ }^{\star} \sim$ housek $\star \sim$ female $\sim$ educ_c ${ }^{\star} \sim$ age_c ${ }^{\star} \sim$ servicew $\star$ housek $\star$ female solution coverage: 0.168297

solution consistency: 0.903552

\section{B. Models for Delivered Service Quality}

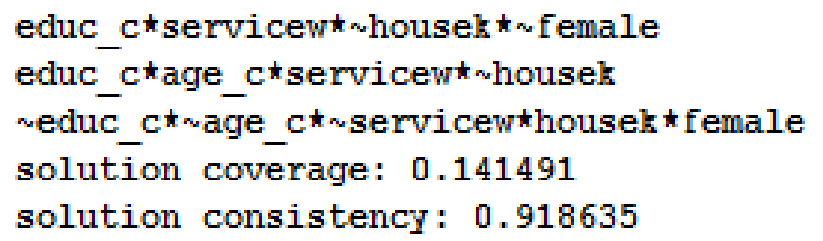

\section{Models for Effective Treatment}

educ_ckservicew» housek $\star \sim$ female educ_ck age_c ${ }^{\star} \sim$ servicew ${ }^{\star}$ housek $\star$ female solution coverage: 0.056061 solution consistency: 0.900138

\section{Models for High Value for the Money}

educ_ckservicew ${ }^{\star} \sim$ housek $\star \sim$ female $\sim$ age_c ${ }^{\star} \sim$ servicew ${ }^{\star}$ housek female $^{\circ}$ $\sim$ educ_ck age_c ${ }^{\star} \sim$ servicew $\approx$ housek $\star \sim$ female solution coverage: 0.095384 solution consistency: 0.897081

$\begin{array}{cll}\begin{array}{c}\text { raw } \\ \text { coverage }\end{array} & \begin{array}{l}\text { unique } \\ \text { coverage }\end{array} & \text { consistency } \\ ------- & -------- & -------- \\ 0.016186 & 0.008217 & 0.968085 \\ 0.106008 & 0.098040 & 0.904675 \\ 0.021131 & 0.021131 & 0.894578 \\ 0.032941 & 0.032941 & 0.897287\end{array}$

raw unique coverage coverage consistency

---------- ---------- ----------
0.015396
0.007849
0.972341
0.101705
0.094159
0.916515
0.031936
0.031936
0.918605

$\begin{array}{cll}\begin{array}{c}\text { raw } \\ \text { coverage }\end{array} & \begin{array}{l}\text { unique } \\ \text { coverage }\end{array} & \begin{array}{l}\text { consistency } \\ -------\end{array} \\ --------- & -------- \\ 0.019602 & 0.019602 & 0.972340 \\ 0.036459 & 0.036459 & 0.865580\end{array}$

\begin{tabular}{cll}
$\begin{array}{c}\text { raw } \\
\text { coverage }\end{array}$ & $\begin{array}{l}\text { unique } \\
\text { coverage }\end{array}$ & $\begin{array}{l}\text { consistency } \\
-0 .---\end{array}$ \\
\hline-017191 & 0.017191 & 0.919149 \\
0.052805 & 0.052805 & 0.862809 \\
0.025388 & 0.025388 & 0.960844
\end{tabular}




\section{Table 11b}

Demographics Indicating High Scores for the Negation of Service Outcomes

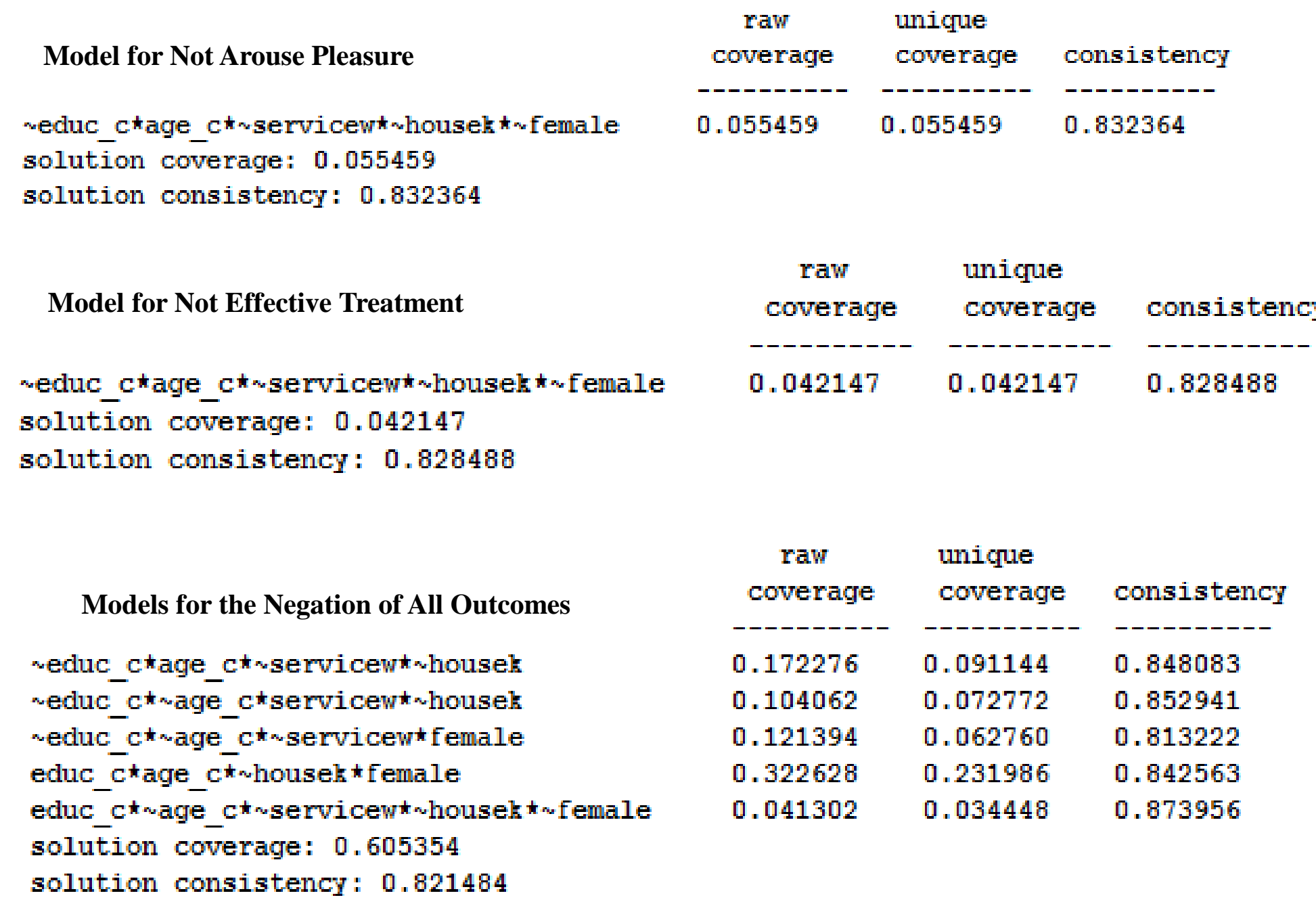

Note. Demographic complex antecedent conditions do indicate consistent negation specific and overall outcome evaluations. Low education occurs in most of these models. High education occurs in the final two models in this table. 
Table 12

Complex Configurations of Service Facet Models Indicating High Scores

for Arouse Pleasure for Subsample 1 and 2

Models from Subsample 1

1 p_disp_ckmusic_ckpeop_s_ckpeopq_c

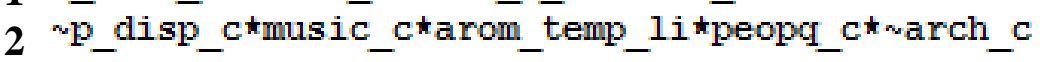

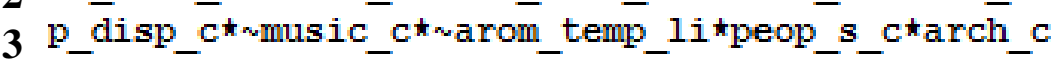

raw unique

coverage coverage consistency

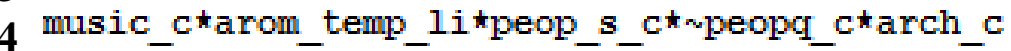

---------

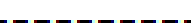

-----------

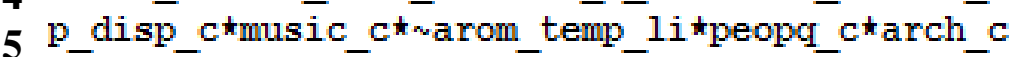

0.184476

0.284139

0.836815

0.142195

0.032283

0.922235

0.210349

0.029235

0.855604

0.165802

0.030016

0.872851

5 $\sim$ p_disp_c ${ }^{\star} \sim$ music_c ${ }^{\star} a r o m$ temp_li

0.104979

0.001094

0.852156

solution coverage: 0.669819

solution consistency: 0.815707

Test of model 1 In subsample 1 using data from subsample 2

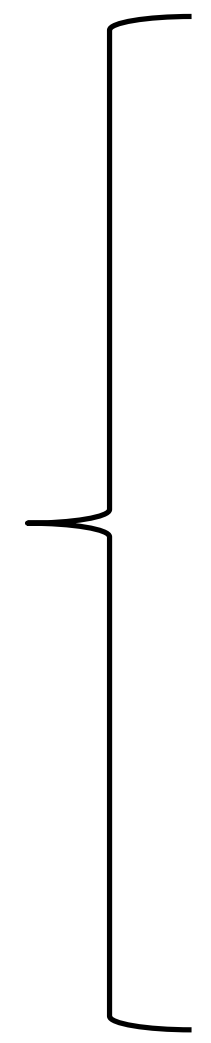

0.923 consistency

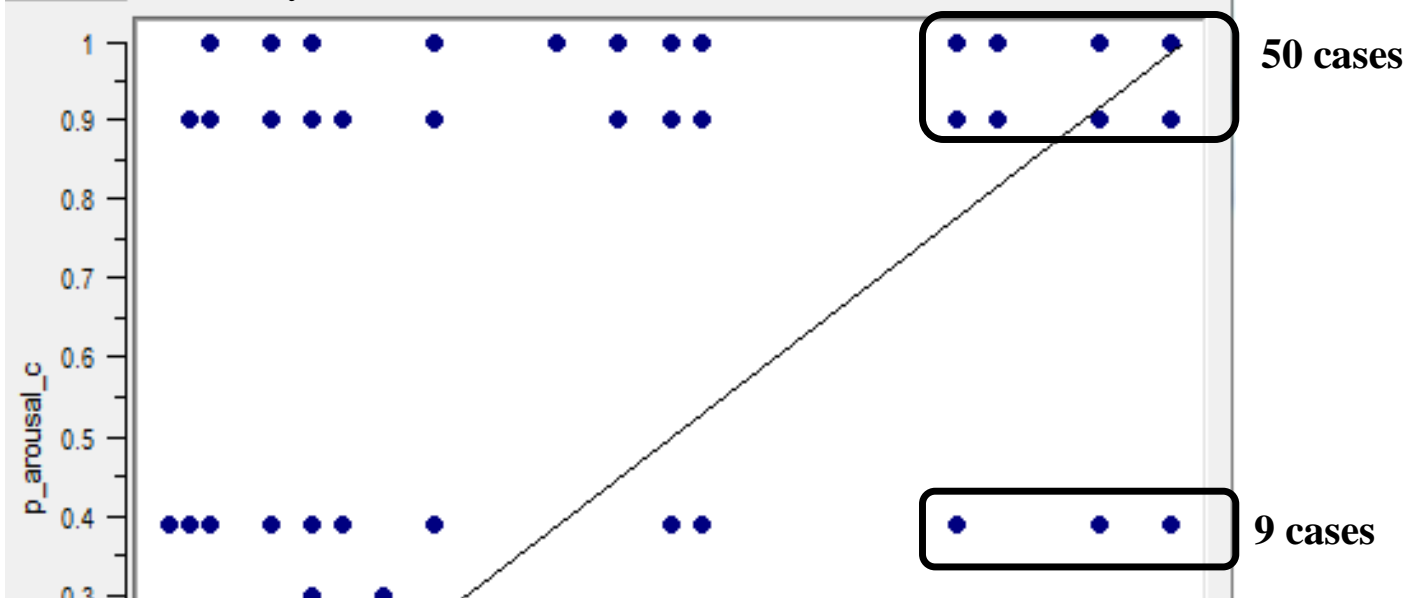

0

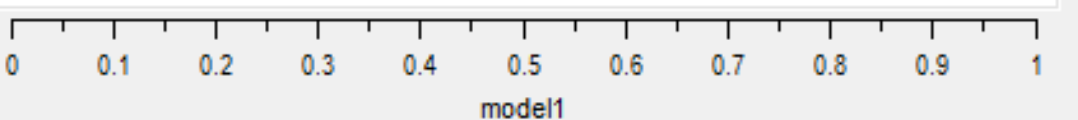

coverage 0.597 